\title{
Distinctive Aspects of the Physical Metallurgy of Warm Rolling
}

\author{
M. R. BARNETT and J. J. JONAS ${ }^{1)}$
}

School of Engineering and Technology, Deakin University, Geelong, Victoria, Australia. E-mail: barnettm@deakin.edu.au

1) Department of Metallurgical Engineering, McGill University, Montreal, Quebec, Canada.

(Received on February 24, 1999; accepted in final form on May 31, 1999)

Warm, or ferritic, rolling is gaining in popularity amongst steel makers as a means of cutting the cost of steel production and opening up the window of hot band properties. The current work presents an overview of some of the more unique, but important, metallurgical aspects of the process. These have been highlighted in a number of laboratory studies that have been conducted over the last decade or so and as yet appear not to have been drawn together in a single article. Certain aspects of the industrial practice of warm rolling are also addressed. But it must be noted that these are somewhat sparse in the literature, presumably due to its status as an emerging, as opposed to widely practised, technology.

KEY WORDS: warm rolling; ferritic rolling; ferrite; deformation; recrystallization; texture; IF steel; low carbon steel.

\section{Introduction}

Over the last decade or so, a number of producers of steel strip have found that considerable benefit can be gained by running their hot strip mills at temperatures 70 or more ${ }^{\circ} \mathrm{C}$ below normal. ${ }^{1,2)}$ This practice, known variously as warm or ferritic rolling, has the potential to broaden the product range and lower the production cost of hot rolled strip. The aim of the present article is to present a brief overview of the physical metallurgy of warm rolled low, extra low and ultra low carbon steels.* Some comments will also be made regarding warm rolling practice.

Changing the rolling temperature from the "hot" to the "warm" regime leads to a considerable change in the physical metallurgy. This is illustrated in the plot of flow stress as a function of deformation temperature given in Fig. 1. ${ }^{3.4)}$ It can be seen that the flow stress increases fairly uniformly with decreasing temperature in the hot rolling region (i.e. at temperatures over $900^{\circ} \mathrm{C}$ ). In the warm rolling regime, however, a number of flow stress peaks, sudden changes and gradient variations are evident. These are indicative of the onset of various metallurgical phenomena.

One of the most significant issues encountered when running a hot strip mill at warm rolling temperatures is summed up in the alternative name coined for the process, ferritic rolling. During, or before, warm rolling, the workpiece undergoes a transformation from the fcc austenite phase to the bcc ferrite phase. This change in structure has a significant impact on the product metallurgy both during and after rolling. It also accounts for the rapid change in flow stress evident around $900^{\circ} \mathrm{C}$ in Fig. 1. The advantages of rolling in the ferrite, as opposed to the austenite, phase include low rolling loads and unique properties in the final hot band product.

The deformation and recrystallization of ferrite are

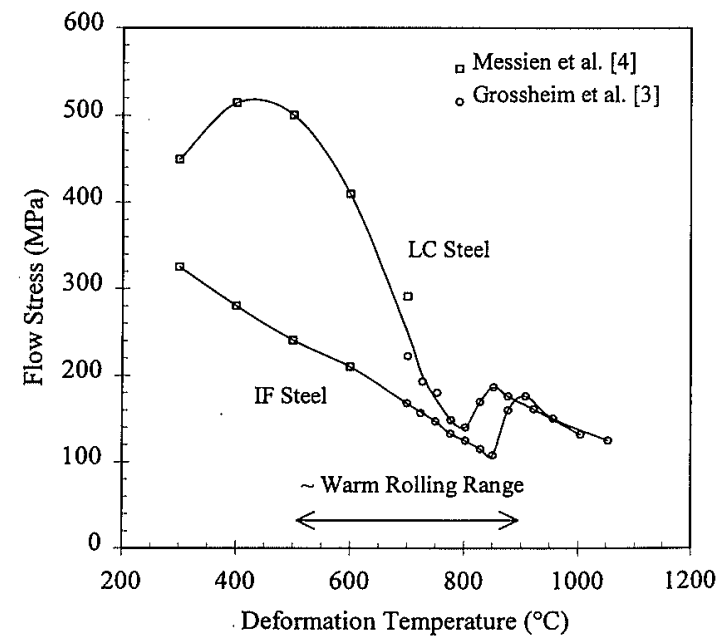

Fig. 1. Influence of deformation temperature on flow stress for LC steel $(0.048 \% \mathrm{C}, 0.24 \% \mathrm{Mn}, 0.047 \% \mathrm{Al}$, $36 \mathrm{ppm} \mathrm{N}^{3)}$ and $0.05 \% \mathrm{C}, 0.23 \% \mathrm{Mn}, 0.035 \% \mathrm{Al}$, $\left.40 \mathrm{ppm} \mathrm{N}^{4}\right)$ and IF material (36 ppm C, $0.12 \% \mathrm{Mn}$, $0.032 \% \mathrm{Al}, 0.056 \% \mathrm{Ti}, 26 \mathrm{ppm} \mathrm{N}^{3)}$ and $30 \mathrm{ppm} \mathrm{C}$, $0.21 \% \mathrm{Mn}, 0.038 \% \mathrm{Al}, 0.081 \% \mathrm{Ti}, 30 \mathrm{ppm} \mathrm{N}^{41}$ ). The peaks and slope changes at the higher temperatures are indicative of transformation, while the peak at the lower temperature in the $\mathrm{LC}$ results is due to dynamic strain aging.

* It turns out that, for the present purposes, the distinction between the behaviours of low carbon and extra low carbon grades is negligible. Consequently, steel grades containing between 0.01 and 0.1 weight percent carbon will be referred to here as low carbon (LC) steels. Stabilised ultra low carbon grades will be referred to as interstitial free (IF) steels. 


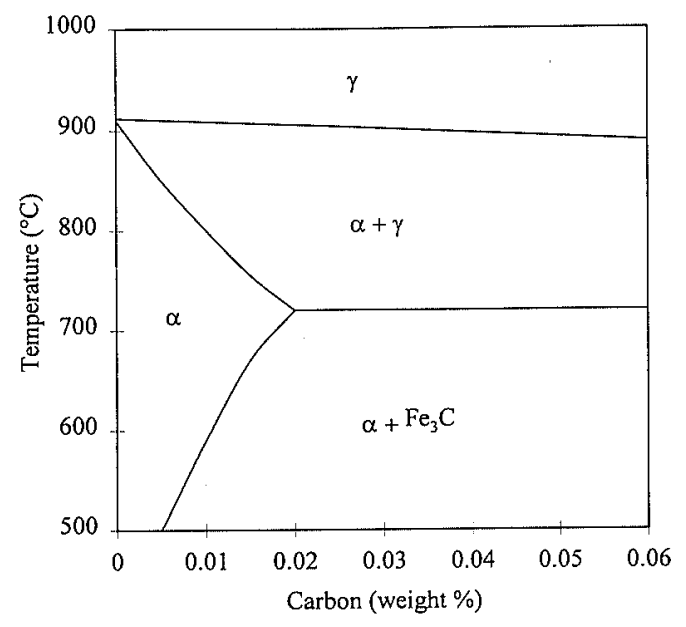

Fig. 2. Fe-C phase diagram covering the temperatures and steel compositions considered here.

therefore an integral part of the physical metallurgy of warm rolling. Consequently, the present review is organised under the headings of: transformation, deformation and recrystallization. Some of the issues associated with these phenomena in warm rolling bear similarities to those seen in either hot or cold rolling. However, these similarities are not of concern here. Rather, emphasis will be placed on reporting work that has highlighted the unique aspects of warm rolling metallurgy (of which there are a surprisingly large number). Wherever simple numerical quantification of the metallurgical processes in question has occurred, these will be quoted.

\section{Transformation}

Because warm rolling entails ferrite deformation, the temperature at which the phase change from austenite to ferrite occurs defines the temperature below which warm rolling can be conducted. The equilibrium phase diagram for the steels considered here is shown in Fig. 2. It is clear that ferrite rolling can only take place below $\sim 900^{\circ} \mathrm{C}$. As can be seen, the lower the carbon content, the greater the tendency to form ferrite.

The situation during rolling is complicated by the cooling rate and the microstructure of the austenite. These must be considered when determining the precise transformation temperature. ${ }^{5)}$ However, as a general rule, warm rolling is often carried out such that the microstructure during the final finishing passes is composed of more than $90 \%$ ferrite. (For a $0.06 \% \mathrm{C}$ grade, the maximum warm rolling finishing exit temperature falls around $780^{\circ} \mathrm{C} .^{1,6)}$ )

Rolling in the region where significant amounts of ferrite and austenite are present forms, at most, a transitory stage during the early stages of warm rolling. However, as would be expected, the presence of austenite during warm rolling has important consequences for the flow stress and the softening of ferrite. With respect to the former, Saito ${ }^{7}$ has found that the flow stress of a ferrite/austenite microstructure can be conveniently described as a weighted average of the individual flow stresses of the two phases. This is illustrated in Fig. 3, which depicts the influence of

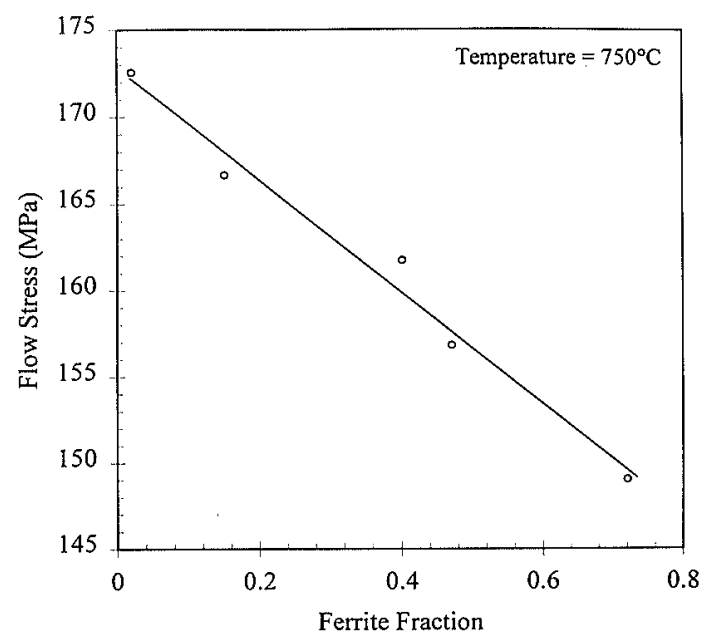

Fig. 3. Linear influence of ferrite fraction on flow stress at a constant deformation temperature of $750^{\circ} \mathrm{C}$ in an LC steel $\left(0.06 \% \mathrm{C}, 1.4 \% \mathrm{Mn}, 0.4 \% \mathrm{Si}, 0.024 \% \mathrm{Al}^{7}\right)$. The ferrite fraction was varied by changing the hold time at $750^{\circ} \mathrm{C}$ after quenching to that temperature.

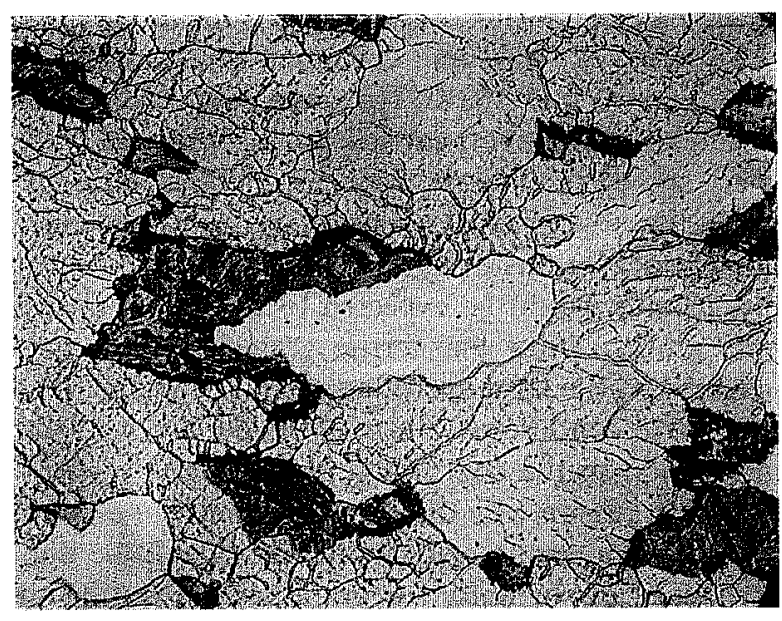

Fig. 4. Recrystallized ferrite grain that appears to have nucleated at the ferrite-austenite interface (magnification $\times 1000$ ). The dark regions were austenite at the deformation temperature (sample from the LC steel used in Ref. 10) $-0.06 \% \mathrm{C}, 0.2 \% \mathrm{Mn}, 0.04 \% \mathrm{Al}, 40$ ppm N).

transformed fraction (varied by changing the hold time prior to deformation) on the flow stress.

With respect to the latter, some workers have reported that recrystallizing grains of ferrite form preferentially, after deformation, at the interface with any remaining austenite. ${ }^{8-10)}$ Some have postulated the occurrence of a transformation-induced recrystallization mechanism. ${ }^{8)}$ This suggestion was based on texture observations thought to be unique to the recrystallization of ferrite in the presence of a small amount of austenite. Other studies have shown, however, that similar textures are formed when austenite is absent. ${ }^{11)}$ Nonetheless, it is likely that austenite islands in a predominantly ferritic structure do indeed enhance the nucleation of ferrite recrystallization. An example of this effect is given in Fig. 4.

It has been suggested that the type of nucleation implied in Fig. 4 contributes to the coarse final grain structures found in warm rolled materials. ${ }^{10)}$ This 


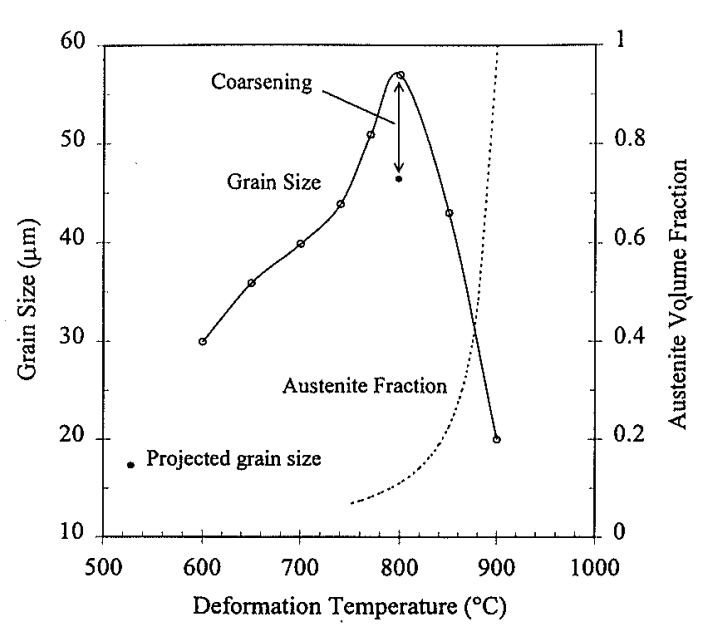

Fig. 5. Influence of compression test temperature on the final grain size after holding at $700^{\circ} \mathrm{C}$ for $25 \mathrm{~min}$ for an LC steel $(0.06 \% \mathrm{C}, 0.2 \% \mathrm{Mn}, 0.04 \% \mathrm{Al}, 40 \mathrm{ppm} \mathrm{N}) .{ }^{101}$ The presence of a small amount of austenite seems to give rise to a coarser final grain size than that projected from the low temperature ferrite data.

coarsening effect is illustrated in Fig. $\mathbf{5}$ for holding times of 25 minutes at $700^{\circ} \mathrm{C}$ and deformation at temperatures between $750^{\circ} \mathrm{C}$ and $800^{\circ} \mathrm{C}$. However, it should be noted that similar experiments carried out by Schmickl et al. ${ }^{12)}$ did not show the same pronounced effect. This could be due to the role played by grain growth. During the completion of transformation after deformation, austenite islands would be expected to transform into fine ferrite grains. These fine ferrite grains may be rapidly consumed by the large surrounding ferrite grains. Under appropriate conditions, this could make a considerable contribution to the coarsening phenomenon evident in Fig. 5. The reason why the data of Schmikl et al. do not display such a strong coarsening effect could be due to the reduced opportunity for grain growth during their short hold times, which were nearly half those used for the data in Fig. 5.

\section{Deformation}

\subsection{Resistance to Deformation (Flow Stress)}

Prediction of the flow stress for a given set of rolling conditions is essential for the production of precisely dimensioned strip. In the case of hot rolling, much work has been carried out on modelling the flow stress as a function of the strain, strain rate and temperature. However, similar work is far from abundant in the warm rolling literature. As briefly touched upon in the introduction and illustrated in Fig. 1, the situation for warm rolling is complicated by the phase transformation and, in the presence of solute carbon, dynamic strain aging (DSA).

The flow stress at the higher ferrite temperatures is expected to lend itself to analyses similar to those applied to other hot rolled materials. In this regard, the peak flow stress $\left(\sigma_{\mathrm{p}}\right)$ during the hot deformation of austenite ${ }^{13)}$ and aluminium ${ }^{14)}$ has been described by a hyperbolic sine law of the form:

$$
Z=A \cdot\left(\sinh \left(\alpha \sigma_{\mathrm{p}}\right)\right)^{n^{\prime}}
$$

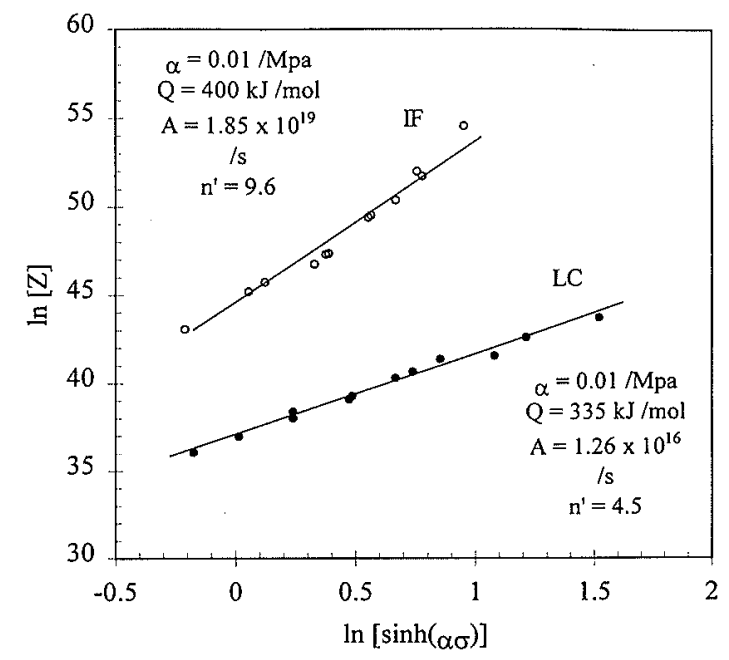

Fig. 6. Flow stresses of an LC steel $(0.048 \% \mathrm{C}, 0.24 \% \mathrm{Mn}$, $0.047 \% \mathrm{Al}, 36 \mathrm{ppm} \mathrm{N}$ ) and an IF grade (36 ppm C, $0.12 \% \mathrm{Mn}, \quad 0.032 \% \mathrm{Al}, \quad 0.056 \% \mathrm{Ti}, \quad 26 \mathrm{ppm} \mathrm{N})^{3)}$ plotted according to the hyperbolic sine flow stress law. The value of $n^{\prime}$ established for the LC grade is half that derived for the IF product.

Table 1. Values for the constants in Eq. (1) for the elevated temperature $\left(\sim 650-850^{\circ} \mathrm{C}\right)$ deformation of ferrite.

\begin{tabular}{cccccc}
\hline Steel & $\mathrm{n}^{\prime}$ & $Q_{\text {def }}(\mathrm{kJ} / \mathrm{mol})$ & $A(/ \mathrm{s})$ & $\alpha$ & Ref. \\
\hline $\mathrm{IF}$ & 9.1 & 460 & $4.5 \times 10^{21}$ & 0.01 & 15 \\
$\mathrm{IF}$ & 9.6 & 400 & $1.85 \times 10^{19}$ & 0.01 & 3 \\
$\mathrm{LC}$ & 4.5 & 335 & $1.26 \times 10^{16}$ & 0.01 & 3 \\
LC & 3.4 & 316 & $4.3 \times 10^{14}$ & 0.01 & 16 \\
\hline
\end{tabular}

where $Z$ is the Zener-Hollomon parameter $\left(\dot{\varepsilon} \cdot \exp \left(Q_{\text {def }}\right)\right.$ $R T), \dot{\varepsilon}$ is the strain rate, $Q_{\text {def }}$ is the activation energy for deformation, $R$ is the gas constant, $T$ is the absolute temperature, and $\alpha, A$ and $n^{\prime}$ are constants. These coefficients were evaluated for ferrite deformation at elevated temperatures using the data reported by Grossheim et $a .^{3)}$ leading to the results displayed in Fig. 6. A reasonably good fit to Eq. (1) is evident in these plots. It is of interest to note that the LC material displays a lower activation energy and $n^{\prime}$ value than the IF steel. This trend is also evident in the data reported by other workers $^{15,16)}$ (see Table 1).

The lower value of the activation energy in the LC steel reflects the contribution to deformation made by the diffusion of carbon, through dynamic strain aging. Similar comments can also be made with regard to the lower value of $n^{\prime} .^{16,17)}$ These effects are elaborated on below.

The exponent $n^{\prime}$ in Eq. (1) is inversely related to the strain rate sensitivity, which is commonly defined as:

$$
m=\frac{\Delta \ln (\sigma)}{\Delta \ln (\dot{\varepsilon})}
$$

For stresses of the order of those found in the data used to determine the coefficients in Table 1 , the following correlation between $n^{\prime}$ and $m$ has been suggested ${ }^{16)}$ :

$$
n^{\prime}=\frac{1}{1.2 \alpha \sigma m}
$$




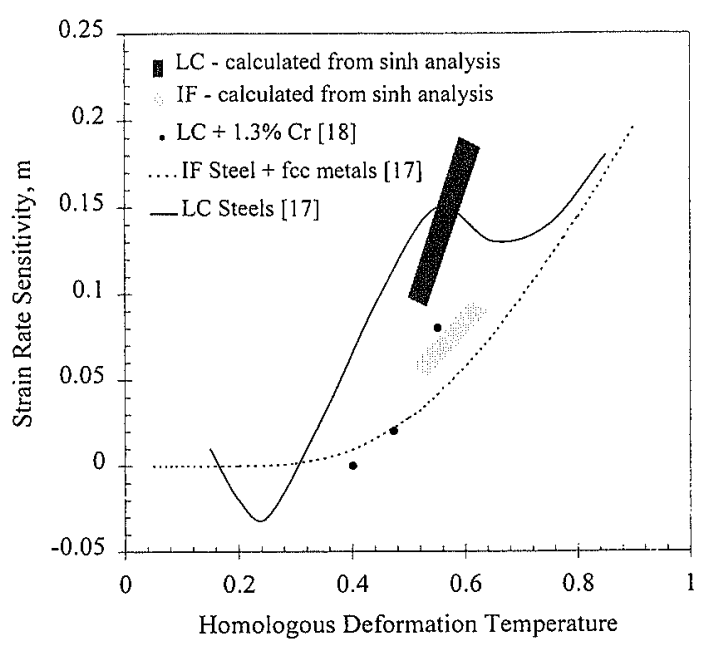

Fig. 7. Influence of homologous temperature on strain rate sensitivity $(m)$ for a number of different materials. ${ }^{17,18)}$ The value of $m$ is considerably higher in LC steels, compared to IF materials, at warm rolling temperatures (i.e. homologous temperatures between 0.5 and $0.65)$.

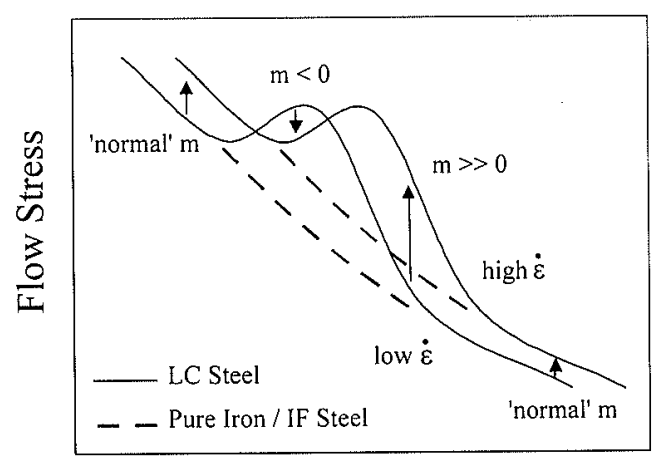

Deformation Temperature

Fig. 8. Schematic representation of temperature $v$ s. flow stress data for two strain rates. The peak in the LC steel curves is a consequence of dynamic strain aging. Examination of the influence of strain rate on the positions of the curves gives an indication of the sign and magnitude of the rate sensitivity parameter, $m$.

The values for $n^{\prime}$ given in Table 1 can therefore be converted into equivalent ones for $m$; the latter are shown in Fig. 7, along with trend lines obtained from work ${ }^{17}$ ) which incorporated the results of both discrete and pseudo-instantaneous* rate change experiments. The IF data are consistent with fcc results, but the low carbon steel data display a distinctly different trend. This difference has been analysed in terms of the influence of solute carbon. ${ }^{17)}$

At high warm deformation temperatures, it appears that grades containing solute carbon display unusually high rate sensitivities. At lower temperatures, the effect is reversed and the presence of solute carbon appears to lead to negative rate sensitivities. These observations can be explained phenomenologically through the use of the tensile stress vs. temperature curves given in Fig. 8. ${ }^{17,18)}$

Observation has shown that an increase in strain rate moves the temperature $v s$. flow stress curve to higher temperatures. ${ }^{19)}$ In the presence of a dynamic strain aging peak, this has a peculiar impact on the rate sensitivity. On the lower temperature side of the peak, an increase in strain rate leads to a lower stress (see Fig. 8). This corresponds to negative rate sensitivity. At temperatures immediately higher than the peak, the steep slope gives rise to an abnormally high positive rate sensitivity. (These effects are absent in an IF steel, represented by the broken line in Fig. 8, due to the fact that no DSA flow stress peak appears in these grades.)

This phenomenon arises because of the influence of deformation temperature on the way in which interstitial atoms interact with mobile dislocations. At intermediate temperatures, carbon atoms diffuse to dislocations during deformation, and interfere with them so as to severely restrict, or prevent, their motion. At higher temperatures, carbon atoms readily move with dislocations as mobile Cottrell atmospheres.

When interstitial atoms are diffusing to dislocations during deformation, an increase in dislocation velocity makes it more difficult for the dislocations to be "caught". Such a phenomenon is likely to be involved in the stress drop caused by strain rate increases in this regime. On the other hand, whenever the interstitial atoms are travelling with mobile dislocations, the retarding force exerted by the impurity atoms is highly sensitive to the dislocation velocity. ${ }^{20)}$ It is reasonable to suppose that this "extra" sensitivity augments the inherent rate dependence of the flow stress.

It is of interest to note that, in the temperature range corresponding to the abnormally high rate sensitivities, the addition of chromium to an LC steel lowers the rate sensitivity to levels similar to those of IF materials $^{18,21)}$ (see Fig. 7). Such an effect can be explained phenomenologically using arguments similar to those applied to Fig. 8 above. Glen ${ }^{22)}$ has shown that the addition of sufficient amounts of $\mathrm{Cr}$ (more than $1.3 \mathrm{wt} \%$ in his case) caused a plateau to appear in the temperature/flow stress curve obtained from tensile tests. Glen's results are reproduced here in Fig. 9. The addition of a second flow stress peak at temperatures immediately above those associated with the C/N DSA peak leads to lower rate sensitivities over this whole temperature range.

The preceding discussion shows that the dramatic influence of carbon on flow stress extends to temperatures higher than those typically associated with DSA and the DSA flow stress peak. This, combined with the fact that the high strain rates encountered under industrial rolling conditions move the DSA peak to higher temperatures, suggests that DSA plays an important role in warm rolling. It has been demonstrated, for instance, that it has a considerable impact on the development of the deformed structure as well as on the evolution of the texture during annealing. These aspects will be discussed in more detail in subsequent sections.

At the temperatures where DSA results in a flow stress

* These tests involved the calculation of the rate sensitivity from instantaneous rate change experiments in which the stress change was established by back extrapolation of the second flow curve. The result is therefore not a truly instantaneous value. 


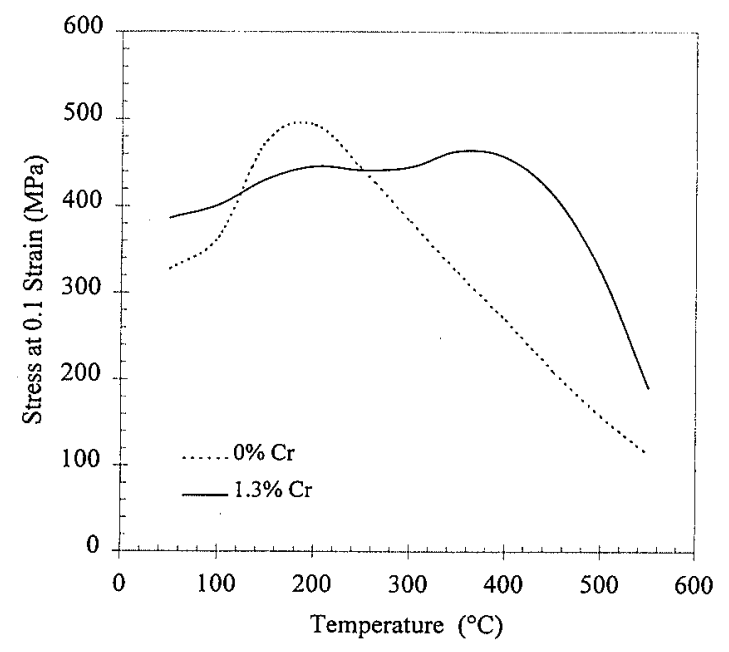

Fig. 9. Temperature $v s$. flow stress curves for tensile test data showing the effect of an addition of $1.3 \% \mathrm{Cr}$ to an LC steel $\left(0.11 \% \mathrm{C}, 0.1 \% \mathrm{Mn}^{22)}\right)$. According to the reasoning illustrated in Fig. 8, the additional peak associated with $\mathrm{Cr}$ addition is expected to extend the region of low rate sensitivity. The onset of abnormally high rate sensitivities will also be postponed to higher temperatures.

peak, modelling the flow stress is a complex task. Attempts to do so have nonetheless been made by Osakada and Fujii. ${ }^{23)}$ The equations derived by these workers for the flow stresses encountered at strains of 0.1 and 0.5 are:

$$
\begin{aligned}
& \sigma_{0.1}=208 \exp \left(\frac{143}{T(1-0.0706 \ln \dot{\varepsilon})}\right) \\
& +118 \exp \left(-45.9\left(\ln \left(\frac{T(1-0.0426 \ln \dot{\varepsilon}}{651}\right)\right)^{2}\right) \\
& +474 C \exp \left(\frac{173}{T}\right) \\
& \sigma_{0.5}=318 \exp \left(\frac{129}{T(1-0.0881 \ln \dot{\varepsilon})}\right) \\
& +127 \exp \left(-28.9\left(\ln \left(\frac{T(1-0.0454 \ln \dot{\varepsilon}}{654}\right)\right)^{2}\right) \\
& +231 C \exp \left(\frac{641}{T}\right)
\end{aligned}
$$

Here $T$ is the absolute temperature, $\dot{\varepsilon}$ is the strain rate and $C$ is the carbon content in weight percent. To calculate the stress at other strains, the following expression was proposed:

$$
\sigma=\exp \left(1.43 \ln \sigma_{0.5}-0.43 \ln \sigma_{0.1}\right) \varepsilon^{0.62 \ln \left(\sigma_{0.5} / \sigma_{0.1}\right)}
$$

where $\varepsilon$ is the strain. These equations were derived from data collected from a number of literature sources. As an arbitrary test of the model, its predictions are compared with the compression results published by Messien et al. $^{4)}$ in Fig. 10. There is good agreement for the data corresponding to temperatures below $600^{\circ} \mathrm{C}$. (See Ref. 24) for the application of Eqs. 4(a)-4(c) to laboratory rolling results.)

Equation 4(b) can be employed to simulate instantane-

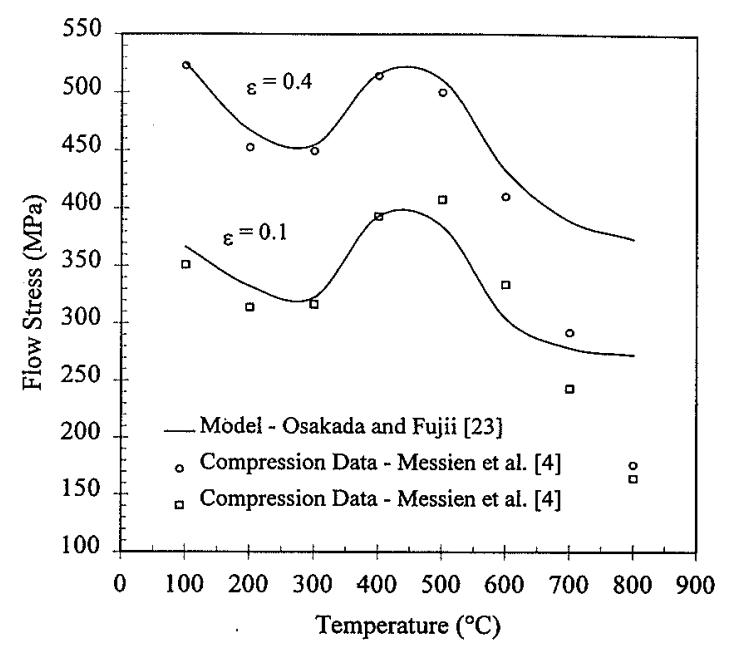

Fig. 10. Comparison between the flow stress predictions based on the model presented in Ref. 23) and data reported by Messien et al. ${ }^{4)}(0.05 \% \mathrm{C}, 0.23 \% \mathrm{Mn}$, $0.035 \% \mathrm{Al}, 40 \mathrm{ppm} \mathrm{N}$ ). Reasonable agreement between the two is obtained for deformation temperatures below $600^{\circ} \mathrm{C}$.

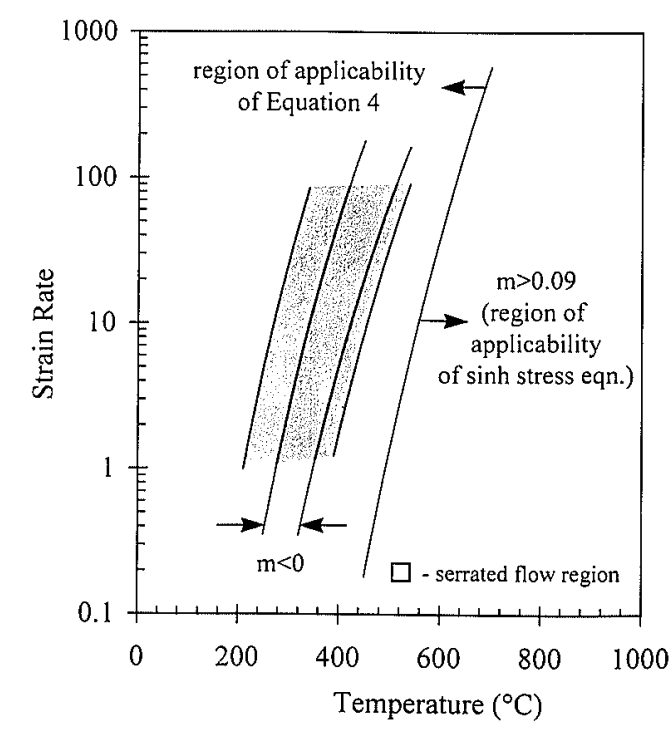

Fig. 11. Deformation map showing the regions of high $(m>0.09)$ and negative rate sensitivities for LC steels, calculated using Eq. 4(b). The region where serrations are expected in high strain rate tensile tests is also shown (based on data in Ref. 25)).

ous strain rate change tests. For rate sensitivities up to around 0.09 , the strain rate sensitivity thus calculated displays a trend similar to that evident in Fig. 7 for the LC steel. It is therefore suggested that Eqs. 4(a)-4(c) only be applied in cases where the rate sensitivity is below this level. This observation can be used to construct a plot that identifies the deformation conditions where the DSA based Eqs. (4a)-(4c) are applicable. Such a map is given in Fig. 11. This figure is also useful for illustrating the combined influence of temperature and strain rate on the regions of negative and high rate sensitivity.

For rate sensitivities above $\sim 0.09$, a model based on the hyperbolic sine law (see Eq. (1)) is more appropriate for LC steels. For warm rolling LC material on typical hot strip mills $(\dot{\varepsilon}<200 / \mathrm{s})$, a hyperbolic sine law can be 


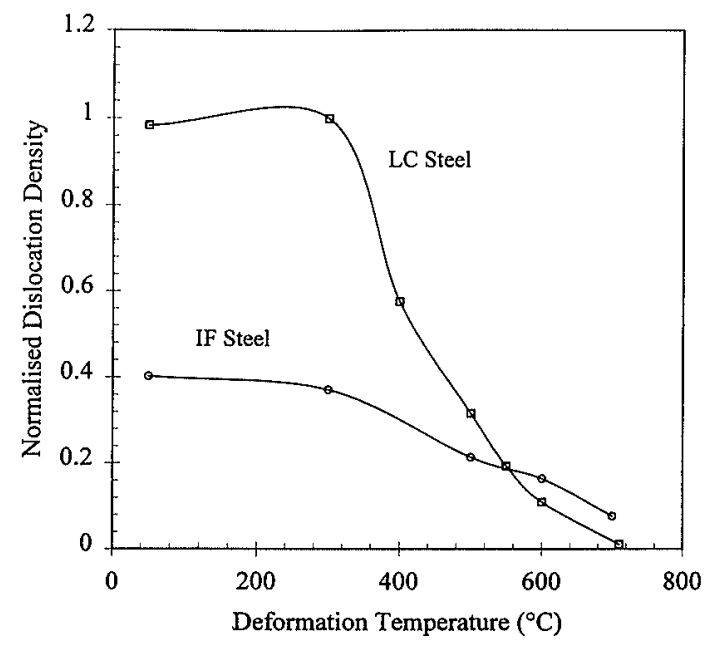

Fig. 12. Influence of rolling temperature on normalised dislocation density, estimated from X-ray line broadening and hardness measurements for an LC grade $(0.014 \% \mathrm{C}, 0.22 \% \mathrm{Mn}, 0.03 \% \mathrm{Si}, 8 \mathrm{ppm} \mathrm{N})$ and an IF steel (50 ppm C, $0.13 \% \mathrm{Mn}, 0.042 \% \mathrm{Al}, 0.084 \%$ $\mathrm{Ti}, 30 \mathrm{ppm} \mathrm{N}){ }^{17}{ }^{17}$ The higher dislocation densities at lower temperatures in the LC grade are due to DSA.

used to predict the deformation stresses for operating temperatures above $600^{\circ} \mathrm{C}$. This temperature is likely to be lower for IF steels, due to the absence of DSA effects.

Figure 11 demonstrates that the rate sensitivity of LC steels, also illustrated in Fig. 7, is a function of temperature. However, that for IF steels is not (at least not to the same degree), due to the absence of DSA effects. From Fig. 7, it can be seen that the rate sensitivity of IF steels is expected to be greater than 0.09 only when the temperature of deformation exceeds $950^{\circ} \mathrm{C}$. This finding can be compared with the region where $m$ is greater than 0.09 for LC steels, as depicted in Fig. 11. It is evident that, even at strain rates around $200 / \mathrm{s}$, LC steels display a higher rate sensitivity than IF material for deformation temperatures above $650^{\circ} \mathrm{C}$.

Maps similar to Fig. 11 have been used to identify the conditions under which serrations appear during tensile testing. ${ }^{25)}$ The serrated flow region extrapolated to higher strain rates from the work of Keh et al. ${ }^{25)}$ is also shown in Fig. 11. It is clear that there is an overlap between the region of negative rate sensitivity and the region of expected serrated flow. Perhaps more importantly for warm rolling, it is clear that negative rate sensitivities can arise if $\mathrm{LC}$ steels are rolled below $\sim 550^{\circ} \mathrm{C}$ at strain rates around $200 / \mathrm{s}$

\subsection{Microstructure after Deformation}

Dynamic recovery is prevalent over a wide range of high temperature ferrite deformation conditions. ${ }^{26,27)}$ (The conditions where dynamic recrystallization becomes important will be explored in the next section.) The deformed structure of warm deformed steel is therefore composed of a recovered arrangement of dislocations.

Several studies have estimated the density of these dislocations in the warm worked structure, using techniques including hardness measurement, $\mathrm{X}$-ray line broadening and TEM analysis. ${ }^{17,25,28)}$ The most significant outcome of these studies is that DSA leads to

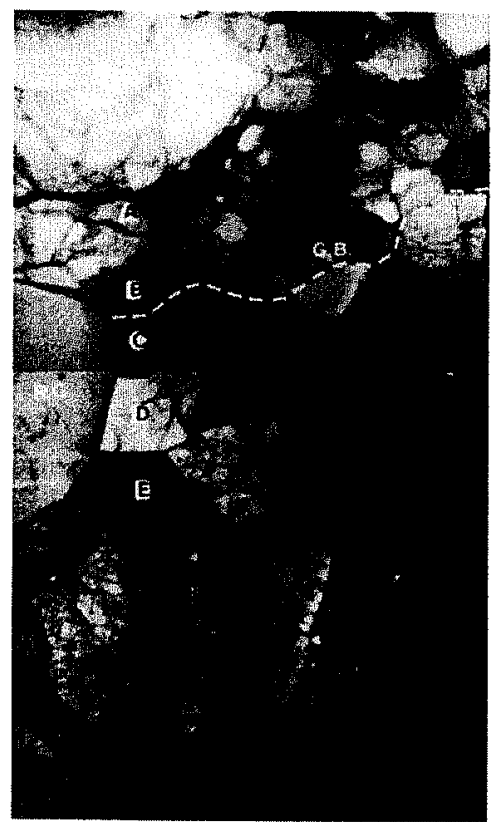

$$
\begin{aligned}
& A=\{111\}<110> \\
& B=\{111\}<110> \\
& C=\{113\}<110> \\
& D=\{112\}<110> \\
& E=\{111\}<110>
\end{aligned}
$$

Fig. 13. TEM image ${ }^{32)}$ illustrating the changes in orientation observed in the grain boundary regions of a warm rolled LC product $(0.01 \% \mathrm{C}, 0.24 \% \mathrm{Mn}, 0.021 \% \mathrm{Al}$, $20 \mathrm{ppm} \mathrm{N}$ )

an appreciable increase in the dislocation density. This effect is illustrated in Fig. 12, ${ }^{17)}$ in which the estimated relative dislocation density is displayed as a function of deformation temperature for an IF and an LC steel warm rolled to a reduction of $65 \%$ in one pass. At the lower temperatures, DSA in the LC material leads to the higher dislocation density.

The dislocation density in warm rolled structures is present largely as a recovered subgrain structure. The sizes of these subgrains have been measured in a number of deformation studies. ${ }^{26,29-31)}$ For stresses ranging between $30 \mathrm{MPa}$ and $300 \mathrm{MPa}$, the subgrain size varies from $6 \mu \mathrm{m}$ down to $\sim 1 \mu \mathrm{m}$.

A peculiarity of the subgrain structure of warm rolled LC materials has been highlighted by Senuma and co-workers. ${ }^{32)}$ In this study, it was observed that the orientations of subgrains in $\{111\}\langle 110\rangle$ deformed grains rotated towards $\{112\}\langle 110\rangle$ near the grain boundaries. A TEM image illustrating this effect is reproduced in Fig. 13. Interestingly, a similar phenomenon was not observed in an IF material processed under the same conditions. This observation has been attributed to the presence of solute carbon during deformation. ${ }^{32)}$

The significance of such orientation gradients is in their role in the formation of the distinct recrystallization textures seen in warm rolled LC product. ${ }^{32)}$ However, it is worth noting that the absence of these distinct textures in a $\mathrm{Cr}$ added $\mathrm{LC}$ grade suggests that the mechanism by which the orientation gradients form may involve more than the presence of solute carbon. ${ }^{18,21,33,34)}$ These 


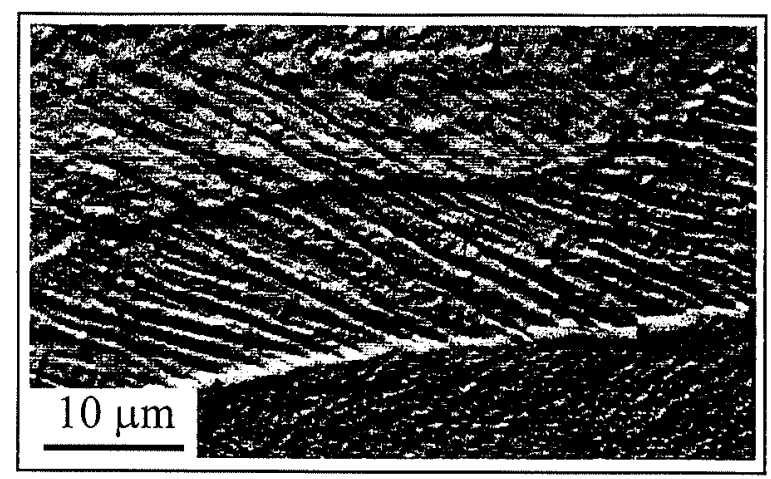

Fig. 14. Example of in-grain shear bands formed in an IF steel (50 ppm C, $0.13 \% \mathrm{Mn}, 0.042 \% \mathrm{Al}, 0.084 \% \mathrm{Ti}, 30$ ppm $\mathrm{N}$ ) rolled to a reduction of $65 \%$ at $700^{\circ} \mathrm{C}$. ${ }^{17)}$

effects will be explored further in the section on recrystallization below.

Warm rolled microstructures also display banded features that are elongated at an angle to the rolling direction. ${ }^{17,35)}$ Similar structures are seen in cold rolled materials and, depending on their nature, are labelled microbands, shear bands, deformation bands, lamellar bands, etc. In their study of a warm rolled IF steel, Akbari et $a{ }^{35)}$ have reported the presence of microbands and shear bands. They noted that the microbands observed in their work all shared a similar macroscopic orientation; i.e. inclinations of + or $-35^{\circ}$ with respect to the rolling plane. This is consistent with the features labelled microbands by Hansen and co-workers for cold rolled fcc materials. ${ }^{36.37)}$ However, similar looking bands identified by Ushioda et al. $^{38)}$ as shear bands in optical analyses of a warm rolled $\mathrm{Fe}-\mathrm{N}$ alloy also displayed similar macroscopic orientations.

Irrespective of the titles given to them by various authors, microstructural bands that have a $20^{\circ}-35^{\circ}$ inclination to the rolling plane and carry localised flow have been shown to play an important role in the metallurgy of warm rolled steel. ${ }^{17,18.34,38)}$ These bands are usually contained within individual deformed grains (see Fig. 14). For the present purpose, the descriptive term "in-grain shear band" will be employed. (N.b. Strictly speaking, microbands are not precluded from this definition because, although this term is not usually applied to a feature supporting localised flow, some authors have reported the occurrence of shear along microbands. ${ }^{39)}$ )

As already indicated above, one of the significant aspects of in-grain shear bands is that they support localised flow. This means that they, like other flow localisation phenomena, are sensitive to the deformation temperature, rate sensitivity and work hardening rate. ${ }^{40)}$ An example of this is found in the work of Ushioda et al. $^{38)}$ These researchers reported an increase in the severity of in-grain type shear bands with the onset of DSA. As illustrated in Fig. 11 above, DSA and tensile flow serrations are accompanied by negative rate sensitivities in the region of the flow stress peak. Negative rate sensitivities enhance the formation of flow localisations. $^{40)}$ (When a localisation begins to form, the strain rate is increased in that region. If the rate sensitivity

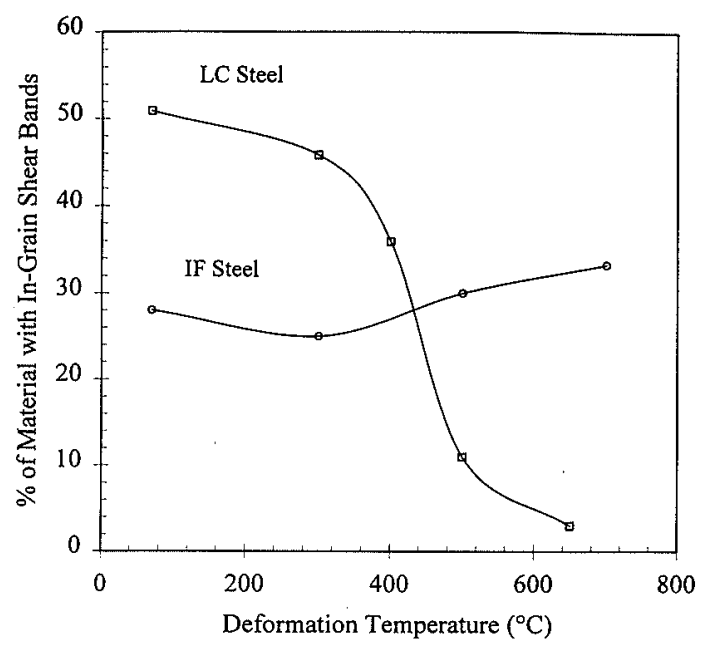

Fig. 15. Influence of deformation temperature on the volume fraction of material containing in-grain shear bands for an IF steel (50 ppm C, $0.13 \% \mathrm{Mn}, 0.042 \% \mathrm{Al}$, $0.084 \% \mathrm{Ti}, 30 \mathrm{ppm} \mathrm{N})$ and an LC grade $(0.014 \% \mathrm{C}$, $0.22 \% \mathrm{Mn}, 0.03 \% \mathrm{Si}, 8 \mathrm{ppm} \mathrm{N}) .{ }^{17}$ There is clearly a greater effect of deformation temperature in the $\mathrm{LC}$ material.

is negative, the flow stress immediately falls, thus giving rise to a rapid acceleration of localised flow.)

Given the marked influence of negative rate sensitivity on the formation of in-grain shear bands, it follows that high positive rate sensitivities should also have a significant effect, with opposite consequences. Indeed, it has been shown that warm rolled LC materials display drops in the frequency of in-grain shear banding with increasing rate sensitivity. ${ }^{17)}$ There is thus a rapid drop in in-grain shear band formation as the temperature is increased from $400^{\circ} \mathrm{C}$ to $600^{\circ} \mathrm{C}(\dot{\varepsilon}=10 / \mathrm{s})$. This is illustrated in Fig. 15, along with IF steel data. In the latter case, there is a negligible influence of temperature on in-grain shear band formation. Of critical importance here is the observation that, at warm rolling temperatures of around $700^{\circ} \mathrm{C}$, the IF steel contains a considerably higher density of in-grain shear bands than the LC grade.

In support of the relationship between rate sensitivity and the frequency of in-grain shear banding, it has been found that the addition of $1.3 \% \mathrm{Cr}$ to an LC steel increases the in-grain shear band fraction from $\sim 0$ to $30 \%$ for a finish rolling temperature of $600^{\circ} \mathrm{C}$. This effect arises from the fact that $\mathrm{Cr}$ addition reduces the rate sensitivity. ${ }^{18)}$

In-grain shear bands have been shown to cause fragmentation of the warm rolled structure. ${ }^{34)}$ As a result, there is a significant difference in the orientation homogeneity of the substructure of warm rolled IF and LC steels. This effect is illustrated in Fig. 16. This figure displays the misorientations over $3 \mu \mathrm{m}$ measured in longitudinal scans carried out on $10\{111\}$ grains from each grade. The misorientations in the IF grade are almost an order of magnitude greater than those seen in the LC material. This difference in grain fragmentation impacts on the bulk deformation texture as well as on the nucleation of recrystallization.

It has been postulated ${ }^{34)}$ that the influence of carbon 


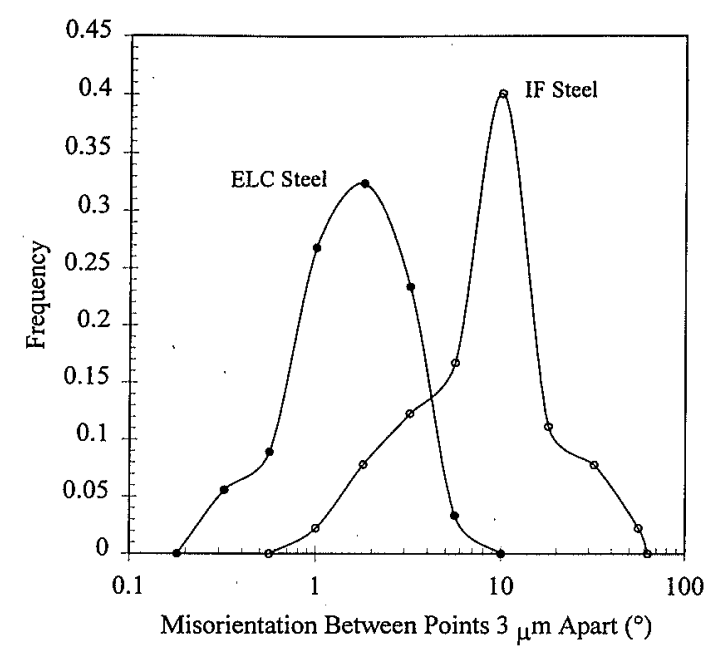

Fig. 16. Comparison of the fragmentation in warm deformed grains in an IF steel $(50 \mathrm{ppm} \mathrm{C}, 0.13 \% \mathrm{Mn}$, $0.042 \% \mathrm{Al}, 0.084 \% \mathrm{Ti}, 30 \mathrm{ppm} \mathrm{N}$ ) and an LC grade $(0.014 \% \mathrm{C}, 0.22 \% \mathrm{Mn}, \quad 0.03 \% \mathrm{Si}, 8 \mathrm{ppm} \mathrm{N})$ expressed as a distribution of misorientations measured using EBSD step scans. ${ }^{34)}$ These were conducted on $10\{111\}$ grains in each material. A greater degree of fragmentation is evident in the IF material.

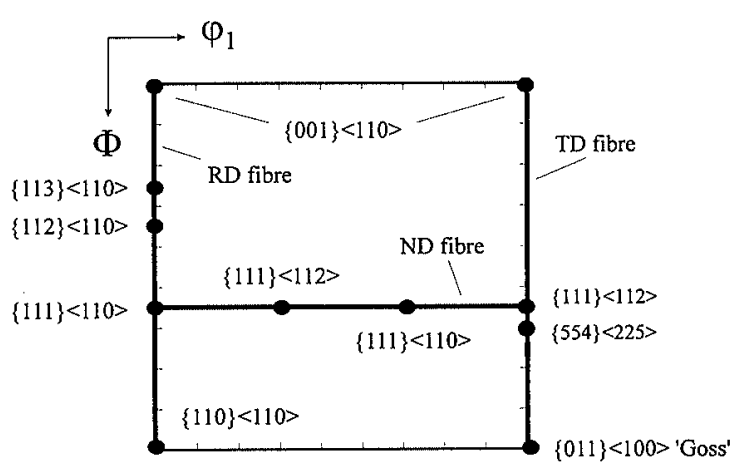

Fig. 17. $\varphi_{2}=45^{\circ} \mathrm{ODF}$ plot showing the locations of the main rolling and recrystallization texture components.

on the rate sensitivity, and of rate sensitivity on in-grain shear band frequency and grain fragmentation plays a large role in the formation of the orientation gradients observed by Senuma et $a l .^{32)}$ It is also true that such subgrain rotations can be expected to be far more visible in the absence of in-grain shear bands. Their apparently anomalous appearance in warm rolled LC materials may therefore simply be a consequence of the ease of identification in the absence of significant amounts of in-grain shear banding in these grades.

\subsection{Bulk Deformation Textures}

The bulk textures of warm rolled materials are similar in form to those displayed by cold rolled products. ${ }^{11,17)}$ The main orientations can be grouped into two families (fibres); those having a $\langle 110\rangle$ axis parallel to the rolling direction ("RD fibre") and those with a $\langle 111\rangle$ axis parallel to the normal direction ("ND fibre" or " $\{111\}$ orientations"). This texture notation is explained in Fig. 17 and some examples of warm rolling textures are provided in Fig. 18. Though the main orientations seem to be the same for the IF and LC steels, it is apparent that increasing the rolling temperature increases the

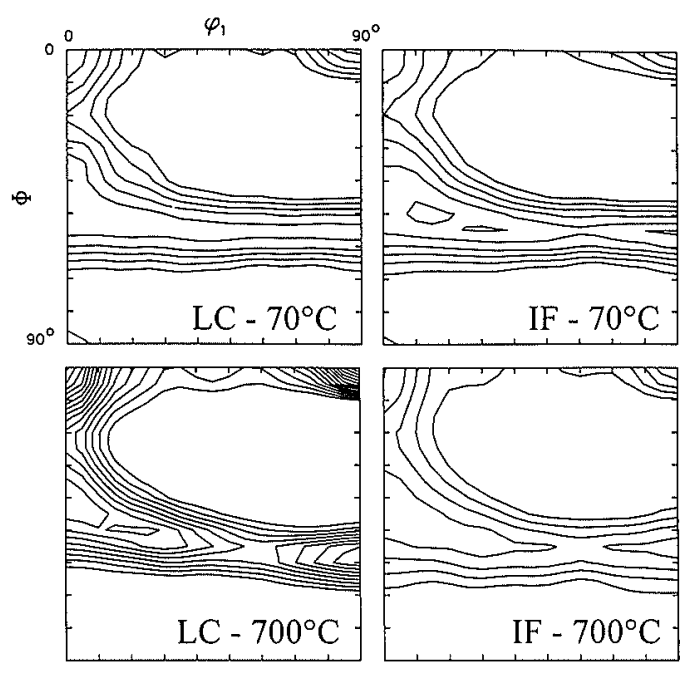

Fig. 18. Deformation textures of an LC steel $(0.014 \% \mathrm{C}$ $0.22 \% \mathrm{Mn}, 0.03 \% \mathrm{Si}, 8 \mathrm{ppm} \mathrm{N}$ ) and an IF grade (50 ppm C, $0.13 \% \mathrm{Mn}, 0.042 \% \mathrm{Al}, 0.084 \% \mathrm{Ti}, 30$ ppm N) after cold and warm rolling. ${ }^{17)}$ The texture sharpness increases with deformation temperature in the LC material $\left(\varphi_{2}=45^{\circ}\right.$ ODF sections, intensity levels: $2,3,4, \cdots)$.

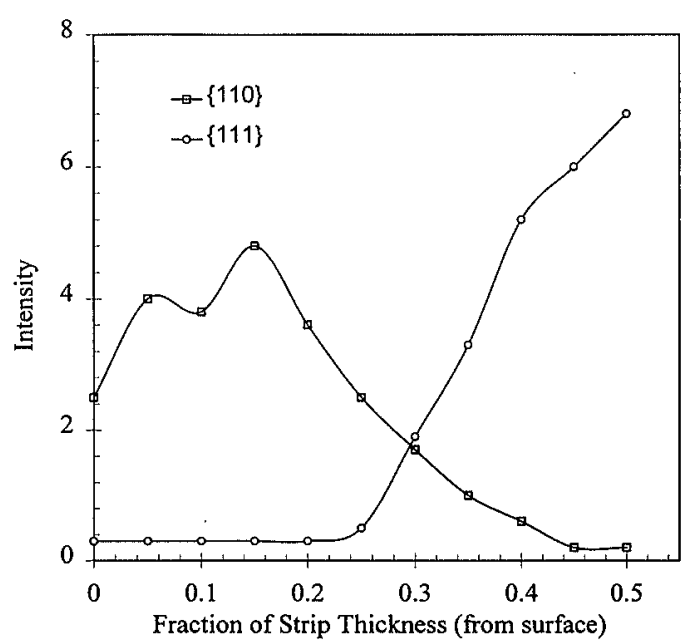

Fig. 19. Variation of rolling texture through sheet thickness of an IF steel $(60 \mathrm{ppm} \mathrm{C}, 0.19 \% \mathrm{Mn}, 0.018 \% \mathrm{Al}$, $0.081 \% \mathrm{Ti}, 43 \mathrm{ppm} \mathrm{N}$ ) due to friction effects. ${ }^{43)}$

texture sharpness in the LC grade. A similar observation was made by Matsuoka et al. $^{41)}$ In their work it, was noted that the sharpness of the rolling texture increased more rapidly with rolling temperature in a $>30 \mathrm{ppm} \mathrm{C}$ grade than in a $10 \mathrm{ppm} \mathrm{C}$ material.

This effect can be rationalised in terms of in-grain shear band formation. ${ }^{17)}$ The fragmentation caused by in-grain shear bands serves to weaken the deformation texture. ${ }^{42)}$ As a consequence of the drop in in-grain shear banding with increasing warm rolling temperature in LC materials, the bulk texture increases rapidly in sharpness with temperature in these grades.

Deformation texture development in warm rolling is also sensitive to friction in the roll bite. It has been shown that high levels of friction during rolling give rise to significant degrees of shear strain near the strip surface. ${ }^{43)}$ The departure of the strain path from plane strain due to this effect alters the evolution of the rolling texture through the strip thickness. Figure $\mathbf{1 9}^{\mathbf{4 3})}$ displays 


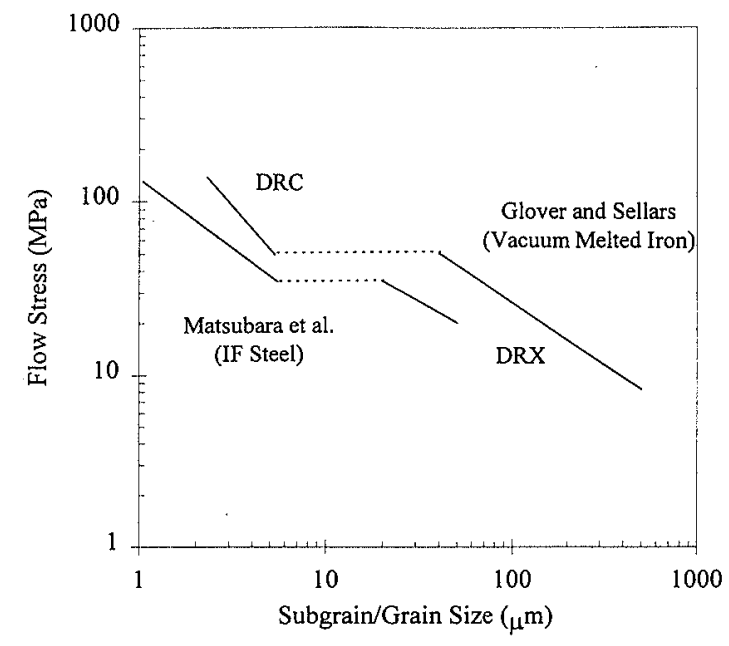

Fig. 20. Grain and subgrain sizes observed immediately following deformation for a vacuum melted iron (45 ppm C, $60 \mathrm{ppm} \mathrm{Mn,} 40 \mathrm{ppm} \mathrm{Al}, 5 \mathrm{ppm} \mathrm{N}^{271}$ ) and an IF grade $(31 \mathrm{ppm} \mathrm{C}, 0.15 \% \mathrm{Mn}, 0.045 \% \mathrm{Al}$, $0.049 \% \mathrm{Ti}, 18 \mathrm{ppm} \mathrm{N}^{31)}$ ). The transition from a dynamically recovered (DRC) structure to a dynamically recrystallized (DRX) one is evident at stresses of around $30-50 \mathrm{MPa}$.

the intensities of the $\{111\}$ and $\{110\}$ components as a function of distance from the strip surface. $\{110\}$ orientations are dominant in the surface regions because this orientation is stable for shear in the rolling direction. ${ }^{44)}$ Further discussion of this phenomenon will be taken up in the section on recrystallization textures below.

\section{Recrystallization}

\subsection{Dynamic Recrystallization}

As mentioned above, the dynamic softening mechanism most commonly identified in the elevated temperature deformation of ferrite is dynamic recovery (DRC). ${ }^{27,45)}$ A number of studies, however, have reported the occurrence of dynamic recrystallization (DRX). ${ }^{27,31,46-49)}$

Conventional "discontinuous" DRX, apparently similar to that seen in hot worked austenite, has been convincingly demonstrated to occur in high purity iron by Glover and Sellars. ${ }^{27}$ ) More recently, similar results have been reported for IF steels. ${ }^{31)}$ These studies are particularly compelling, in part, because they identify a clear transition from DRC to DRX behaviour. This transition is illustrated in Fig. 20. Both studies identified a stress below which the scale of the structure immediately after deformation changes dramatically. This strongly suggests a change in softening mechanism. The presence of high angle grain boundaries, dislocations within newly formed grains and distinctive flow curves, all of which support the occurrence of DRX, were also observed to varying degrees in these studies. ${ }^{27.31)}$

From the results in Refs. 27) and 31), it is possible to construct a deformation map that identifies the conditions under which conventional DRX is expected to occur (see Fig. 21). It is clear that DRX is initiated in the high purity iron at lower temperatures and higher strain rates than in the IF steel. This difference most

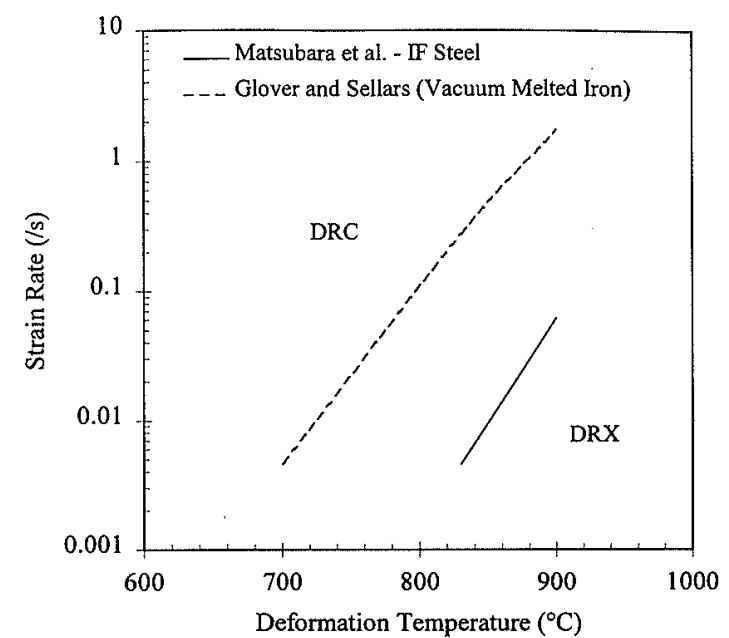

Fig. 21. Deformation map distinguishing between the regions of operation of dynamic recovery (DRC) and conventional dynamic recrystallization (DRX). ${ }^{27.31}$ The lines depict the deformation conditions that give rise to the transition stress identified in Fig. 20.

probably arises from the action of solute and precipitate drag in the IF material. It is of interest to note from Fig. 21 that conventional DRX is unlikely to occur under typical warm rolling conditions (i.e. strain rates between $20 / \mathrm{s}$ and $200 / \mathrm{s}$ and temperatures between $600^{\circ} \mathrm{C}$ and $\left.850^{\circ} \mathrm{C}\right)$.

In apparent contradiction with this analysis, a number of workers have reported that DRX occurs well within the DRC region of Fig. 21. ${ }^{46-49)}$ For example, NajafiZadeh et ll $^{47)}$ have identified the fine grains observed after the multipass warm torsion testing of some IF steels as "dynamically recrystallized" grains. The latter ranged in size from $1 \mu \mathrm{m}$ to $5 \mu \mathrm{m}$ and were deformed at von Mises equivalent stresses of $90 \mathrm{MPa}$ to $220 \mathrm{MPa}$. These parameters correspond closely to those associated with dynamic recovery in Fig. 20. It is likely that another type of DRX is involved here, similar to the "continuous" DRX reported by Gourdet and Montheillet. ${ }^{50)}$

A common feature of these other forms of DRX is that they require higher strains for their initiation than "continuous" DRX. In the case of the results of Najafi-Zadeh et al. ${ }^{47)}$ and in similar observations made by Baczynski and Jonas, ${ }^{46)}$ strains in excess of 3 were involved. This is consistent with the view that this sort of DRX can be understood as a kind of recovery process by means of which a structure consisting of low angle boundaries is gradually converted into one dominated by high angle misorientations. Though it cannot be stated with absolute certainty, it appears that the high strains (and low values of the Zener-Hollomon parameter) at which this mechanism is observed put it outside the conditions likely to be encountered in commercial warm rolling.

Other workers ${ }^{48,49)}$ have suggested that DRX can occur in steels warm rolled in the two phase region under conditions expected to give rise to DRC. It seems that the sandwiching of "soft" ferrite between regions of "hard" austenite can lead to the development of a structure with high angle boundaries as long as the rolling strain is sufficiently high ( $>85 \%$ reduction). In the case 

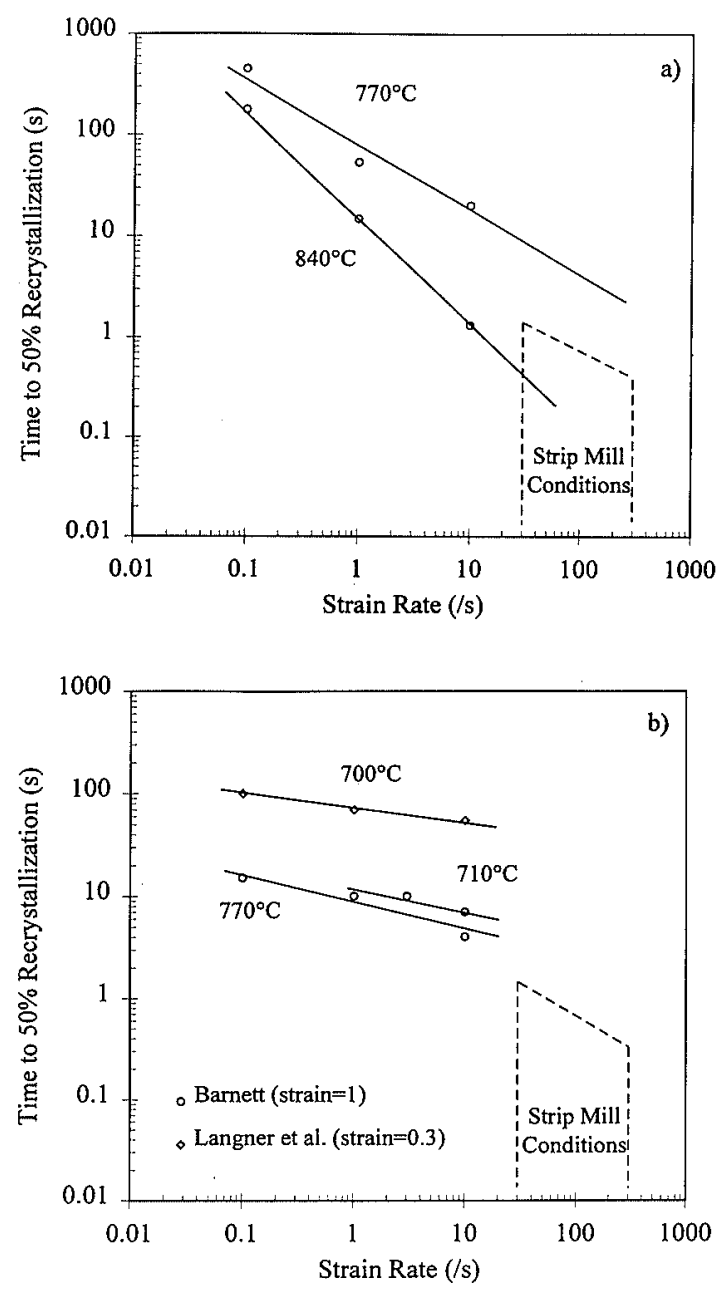

Fig. 22. Influence of strain rate on the time to $50 \%$ static recrystallization for a) an IF steel $(30 \mathrm{ppm} \mathrm{C}$, $0.18 \% \mathrm{Mn}, 0.054 \% \mathrm{Al}, \quad 0.02 \% \mathrm{Nb}, 0.018 \% \mathrm{Ti}, 20$ ppm $\mathrm{N}^{51)}$ ) and b) two LC grades (0.06\% C, $0.2 \% \mathrm{Mn}$, $0.04 \% \mathrm{Al}, 40 \mathrm{ppm}^{52)}$ and $0.022 \% \mathrm{C}, 0.18 \% \mathrm{Mn}$, $0.034 \% \mathrm{Al}, 26 \mathrm{ppm}^{53)}$ ). Intrusion of the extrapolated trends into the dashed region indicates that a degree of interpass softening is likely to occur during rolling.

of one of these studies, ${ }^{48)}$ the average size of the structure was reported as $1.8 \mu \mathrm{m}$. This is well within the range of cell sizes observed in dynamically recovered structures. The mechanism responsible for these findings may also involve "continuous" DRX. According to this view, the combination of heavy rolling reduction and strain concentration in the softer ferrite phase enables the critical strain required for this mechanism to be exceeded.

\subsection{Static Recrystallization-Kinetics}

In conventional hot rolling, knowledge of the kinetics of recrystallization is necessary for accurate prediction of the flow stress. For typical cold rolled products, an understanding of the recrystallization kinetics is required to ensure that complete softening occurs during annealing. Both of these issues impact on warm rolling, which can involve interpass recrystallization during rolling as well as recrystallization during subsequent annealing.

Unlike the case of austenite, kinetic models applicable to interpass recrystallization are scarce in the ferrite literature. However, there are sufficient results available to demonstrate that such recrystallization is likely to be an issue during high temperature warm rolling. The influence of strain rate on the time to $50 \%$ recrystallization is shown in Fig. 22 for an IF and an LC steel. $^{51-53)}$ Extrapolation of these data to the conditions expected in finish rolling suggests that, for rolling temperatures above $\sim 800^{\circ} \mathrm{C}$, some degree of interpass recrystallization is expected to occur in both grades. It should be mentioned, however, that the IF results in Fig. 22 were corrected to remove the effects of concurrent precipitation. ${ }^{51)}$ In a practical situation, the temperature below which interpass recrystallization does not occur will be somewhat higher than that indicated in Fig. 22(a).

The data shown in Fig. 22(b) have been combined with other data to establish a rough model for the time to $50 \%$ recrystallization ( $t_{50}$, in seconds) of LC ferrite in the absence of significant effects of AlN precipitation ${ }^{52)}$.

$$
t_{50}=6 \times 10^{-13} d_{0}^{1.5} \varepsilon_{\mathrm{ps}}^{-2.5} Z^{-0.3} \exp \left(\frac{245000}{R T_{\mathrm{rx}}}\right)
$$

Here $d_{0}$ is the initial grain size in microns, $\varepsilon_{\mathrm{ps}}$ is the plane strain (this is set to 1.1 times the strain to the steady state when it exceeds this value), $Z$ is the Zener-Hollomon parameter (see Eq. (1)), and $T_{\mathrm{rx}}$ is the absolute (holding) recrystallization temperature. The equation is applicable to the recrystallization of a $0.06 \% \mathrm{C} \mathrm{Al-killed}$ LC steel. It should be emphasised, however, that considerable further work is required in this area. In particular, the influence of the concurrent precipitation of AlN should be taken into account. It is also worth noting that initial attempts to include this type of model in a microstructural evolution model have been hampered by the difficulty in predicting the initial grain size accurately during multipass deformation in the twophase region. ${ }^{52)}$ It appears that interactions between the ferrite and austenite phases at low ferrite fractions may have a significant effect on the restoration kinetics. ${ }^{52)}$

With respect to the kinetics of recrystallization during a subsequent annealing stage (when recrystallization has not occurred during coiling), a number of studies have revealed a distinct difference between the behaviours of IF and LC steels. ${ }^{11,54)}$ This, of course, is as would be expected; IF grades typically contain a large number of fine precipitates and LC grades typically do not. It has been suggested, however, that the presence of solute carbon in the LC steels also plays a large role. ${ }^{54)}$ The times for $50 \%$ recrystallization of an IF and an LC grade after single pass rolling (65\% reduction) and during isothermal annealing at $700^{\circ} \mathrm{C}$ are shown in Fig. 23. It is evident that the IF material exhibits slower recrystallization kinetics overall, as indicated above. It is also clear that the influence of temperature is significantly different for the two grades.

The reason for this observation lies with the influence of DSA on the dislocation density after rolling when solute $\mathrm{C}$ is present. At lower temperatures, where DSA is most active, the dislocation density after rolling is abnormally high. This serves to increase the driving force for recrystallization and enhances the influence of deformation temperature on the recrystallization kinetics 


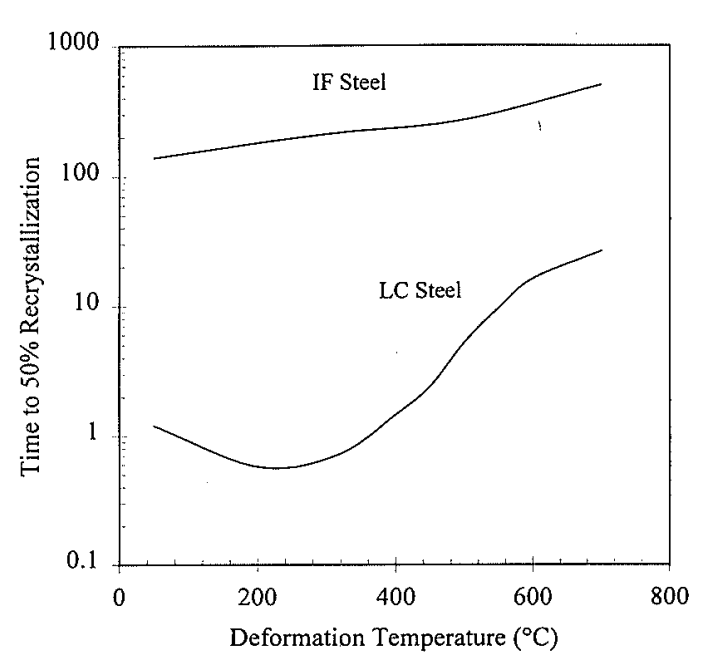

Fig. 23. Influence of deformation temperature on the time to $50 \%$ recrystallization at $700^{\circ} \mathrm{C}$ for an IF steel $(50 \mathrm{ppm}$ $\mathrm{C}, 0.13 \% \mathrm{Mn}, 0.042 \% \mathrm{Al}, 0.084 \% \mathrm{Ti}, 30 \mathrm{ppm} \mathrm{N})$ and an LC grade $(0.014 \% \mathrm{C}, 0.22 \% \mathrm{Mn}, 0.03 \% \mathrm{Si}, 8 \mathrm{ppm}$ N). ${ }^{54}$ There is a greater effect of deformation temperature in the LC material.

Table 2. Values for the constants in Eq. (6) for recrystallization after the elevated temperature deformation of LC ferrite.

\begin{tabular}{cccccc}
\hline Ref. & $B$ & $a$ & $b$ & $c$ & $Q_{\text {def }}(\mathrm{kJ} / \mathrm{mol})$ \\
\hline 10 & 23.7 & -0.7 & 0.55 & -0.06 & 280 \\
12 & 12.9 & -0.45 & 0.55 & -0.03 & 280 \\
56 & - & -0.4 & - & -0.07 & 280 \\
\hline
\end{tabular}

of LC materials. As a consequence, the industrial (continuous) annealing temperature required for the recrystallization of warm rolled LC grades is significantly $\left(\sim 75^{\circ} \mathrm{C}\right)$ higher than that used after cold rolling. ${ }^{55) *}$ For IF steels, where the levels of solute $\mathrm{C}$ are low, the annealing temperature required for warm rolled material is only marginally higher $\left(\sim 25^{\circ} \mathrm{C}\right)$ than that of cold rolled product.

\subsection{Statically Recrystallized Grain Size}

In multipass rolling, the recrystallized grain size influences the recrystallization kinetics after subsequent deformation. The final recrystallized grain size also has a significant influence on the mechanical properties of the product. Due to the importance of these effects, particularly the latter, a number of empirical grain size models have been derived for LC materials. ${ }^{10.12)}$ These have the form:

$$
d_{\mathrm{rx}}=B \varepsilon^{a} d_{0}^{b} Z^{c}
$$

where $d_{\mathrm{rx}}$ is the recrystallized grain size, $\varepsilon$ is the equivalent strain, $d_{0}$ is the "initial" grain size, $Z$ is the ZenerHollomon parameter and $B, a, b$, and $c$ are constants. The values derived by various workers ${ }^{10,12,56)}$ for these constants are given in Table 2 (the activation energy used to calculate $Z$ in these studies was $280000 \mathrm{~kJ} / \mathrm{mol}$ ).

The recrystallized grain size after the subsequent an-

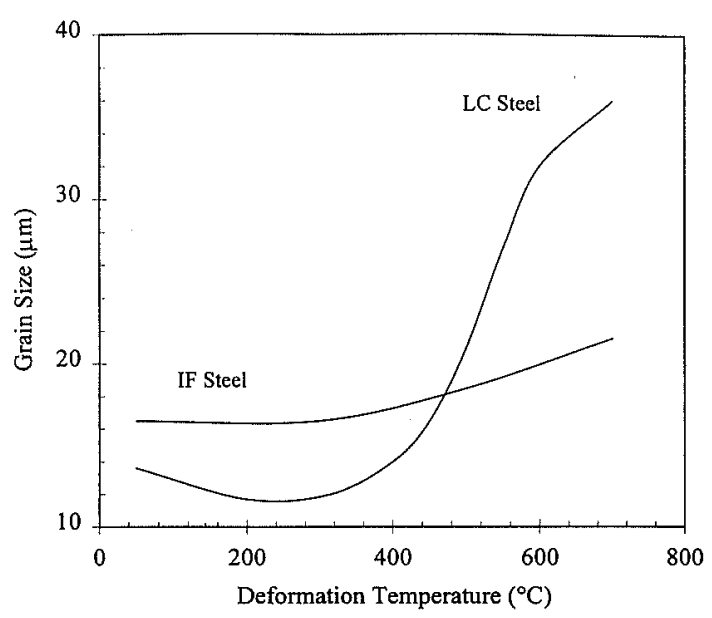

Fig. 24. Influence of rolling temperature on the recrystallized grain size ${ }^{54)}$ for the same steels as those used in Fig. 23. There is a greater effect of deformation temperature in the LC material

nealing of rapidly cooled warm rolled steels has also been studied. ${ }^{54)}$ This work shows that the influence of deformation temperature is very different in an IF steel than in an LC grade. Data showing this effect are presented in Fig. 24. At low deformation temperatures, the IF material displays a coarser recrystallized grain size than the LC product. At higher warm rolling temperatures, this effect is reversed and a coarser grain size is observed in the LC steel. These observations can be explained, in part, in terms of the influence of deformation temperature on the density of in-grain shear bands (see Fig. 15). These bands stimulate the nucleation of recrystallization. The greater the volume fraction of in-grain shear bands, the finer the recrystallized grain size. The rapid coarsening of recrystallized grain size with increasing deformation temperature in the LC material is therefore explained by the dramatic drop in in-grain shear band density that accompanies the temperature change.

\subsection{Recrystallization Textures}

Probably one of the most perplexing and troublesome aspects of the metallurgy of warm rolling is the extraordinarily low range of $r$ values produced in LC products. This effect, of course, is related to the nature of the recrystallization texture. In this regard, two important issues have been highlighted; i) the recrystallization texture at the mid-plane of the sheet is very sensitive to the presence of solute carbon during deformation, and ii) the recrystallization texture at the surface of the sheet is strongly dependent on frictional effects during rolling. These are discussed in turn below.

\subsubsection{Midplane Textures}

The influence of rolling temperature on recrystallization texture for an LC and an IF steel is shown in Fig. $25{ }^{54)}$ It is clear that changing the rolling temperature has a larger effect on the LC grade than on the IF steel. In particular, the $\{111\}$ or ND fibre intensity decreases

* The evidence of DSA effects at room temperature is made possible by the diffusion of $\mathrm{C}$ along dislocations, deformation heating and high solute carbon levels. ${ }^{17.25)}$ 


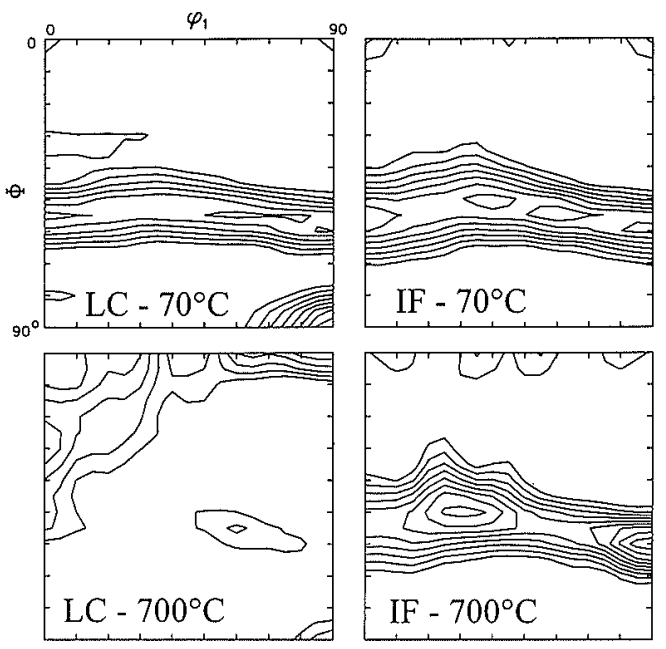

Fig. 25. Recrystallization textures corresponding to an IF steel (50 ppm C, $0.13 \% \mathrm{Mn}, 0.042 \% \mathrm{Al}, 0.084 \% \mathrm{Ti}, 30$ ppm $\mathrm{N})$ and an LC grade $(0.014 \% \mathrm{C}, 0.22 \% \mathrm{Mn}$, $0.03 \% \mathrm{Si}, 8 \mathrm{ppm} \mathrm{N}){ }^{54)}$ The difference between the LC results and those of the IF grade is most evident at $700^{\circ} \mathrm{C}\left(\varphi_{2}=45^{\circ}\right.$ ODF sections, intensity levels: 2 , $3,4, \cdots)$.
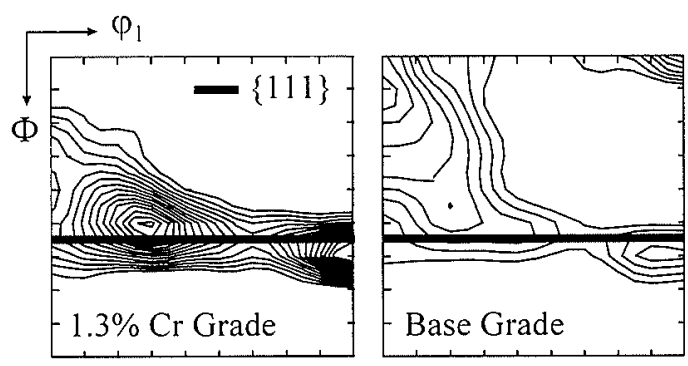

Fig. 26. Illustration of the influence of $1.3 \mathrm{w} 1 \% \mathrm{Cr}$ addition on the recrystallization texture of a warm rolled LC steel $\quad(0.032 \% \mathrm{C}, \quad 0.13 \% \mathrm{Mn}, \quad 0.04 \% \mathrm{Al}, \quad 25 \mathrm{ppm}$ N). ${ }^{18.21)}$ The Cr-added material is characterised by a higher $\{111\}$ intensity $\left(\varphi_{2}=45^{\circ}\right.$ ODF sections, intensity levels: $2,3,4, \cdots)$.

significantly with increasing temperature in the LC grade. After rolling at $700^{\circ} \mathrm{C}$, the recrystallization texture of the LC material contains negligible amounts of the desirable $\{111\}$ component. This is significant because steel owes its favourable drawing properties, as expressed by the $r$-value, to its strong $\{111\}$ texture.

The low $\{111\}$ intensities in warm rolled LC materials were first studied by Senuma et al. ${ }^{32)}$ who concluded that they arose from the presence of solute carbon during rolling. As mentioned above, these workers observed that abnormal subgrain rotations occurred in regions close to the grain boundaries in warm rolled LC products. These orientation gradients were considered to be the cause of the change in the recrystallization texture. The orientation gradients, in turn, were thought to arise from the interaction of solute carbon and slip events during deformation.

However, more recently, it has been shown that the $\{111\}$ recrystallization texture can be restored to $\mathrm{LC}$ material, without removing the carbon from solution. ${ }^{18,21)}$ Figure 26 illustrates the influence of $\mathrm{Cr}$ addition on the recrystallization texture of a laboratory warm rolled

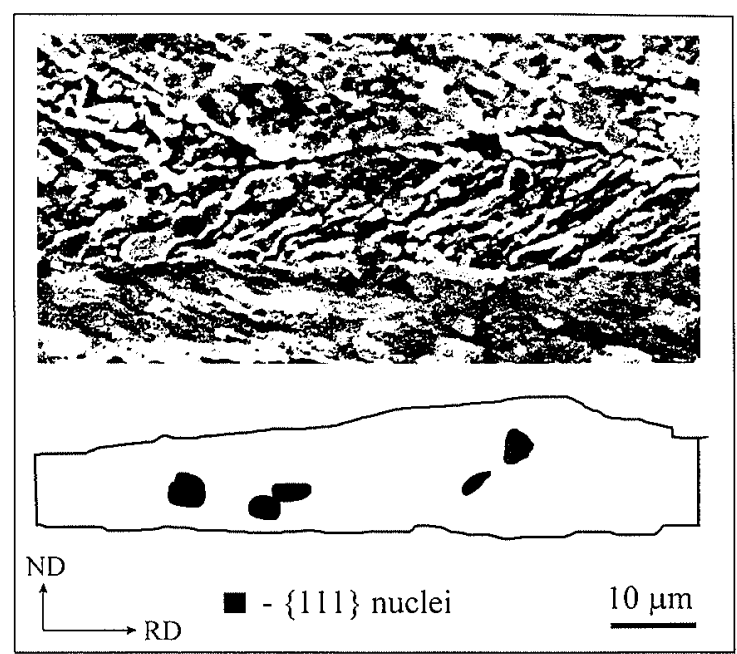

Fig. 27. An example of $\{111\}$ recrystallization nuclei forming in in-grain shear band structures in an IF stecl $(50 \mathrm{ppm}$ C, $0.13 \% \mathrm{Mn}, 0.042 \% \mathrm{Al}, 0.084 \% \mathrm{Ti}, 30 \mathrm{ppnn}$ N). ${ }^{34)}$ The samples were deformed at $700^{\circ} \mathrm{C}$ and partially annealed at the same temperature. The image was produced using orientation contrast BSE imaging.

LC steel $\left(85 \%\right.$ reduction in five passes between $750^{\circ} \mathrm{C}$ and $600^{\circ} \mathrm{C}$ followed by "coiling" at $400^{\circ} \mathrm{C}$ and "batch annealing" at $700^{\circ} \mathrm{C}$ for five hours). It is clear that the $\mathrm{Cr}$ grade gives rise to a texture very similar to that seen in IF materials. This suggests that it is not solute carbon, per se, that causes the recrystallization texture of warm rolled LC to differ so markedly from those of cold rolled and annealed LC materials and warm rolled and annealed IF products.

The absence of a distinct $\{111\}$ recrystallization texture in warm rolled LC material correlates with the absence of in-grain shear bands. ${ }^{54)}$ When in-grain shear band fractions are increased, by decreasing the rate sensitivity (i.e. by removing the carbon from solution or by adding $\mathrm{Cr})$, a $\{111\}$ recrystallization texture is formed. ${ }^{18)}$ This supports the view that the presence of in-grain shear bands stimulates the formation of $\{111\}$ components during the recrystallization of warm rolled steels.

Such a conclusion is further supported by a study conducted into the nucleation of $\{111\}$ grains in a warm rolled IF steel. ${ }^{34\}}$ Some results of this work are presented in Fig. 27. In this investigation, $\{111\}$ oriented nuclei were seen to form within in-grain shear band structures. A similar type of nucleation was also observed by Duggan et al. $^{57)}$ in a cold rolled ULC steel. This is also consistent with the growing number of studies emphasising that the nucleation of $\{111\}$ grains can take place in the interiors of deformed grains. ${ }^{58,59)}$

The effects of $\mathrm{Ti}$ and solute carbon on the nucleation of recrystallization in warm rolled steels have been examined by Senuma et al. $^{32)}$ Figure 28 illustrates the relative frequency of two types of nucleation occurring in various warm rolled materials. Nucleation at $\{111\}$ grain interior sites as well as that arising from the "bulge" nucleation mechanism, which typically involves the protrusion of $\{001-112\}\langle 110\rangle$ regions into $\{111-110\}\langle u v w\rangle$ grains, is depicted. ${ }^{32)}$ The presence of solute carbon correlates with a decrease in $\{111\}$ grain 


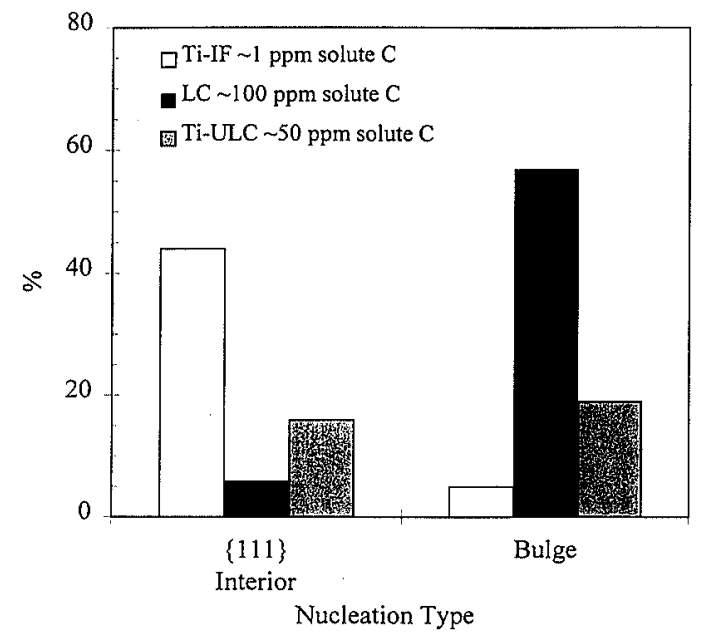

Fig. 28. Percentage of the total number of nuclei that were seen in $\{111\}$ grain interiors, or operating by the "bulge" mechanism, during annealing after warm rolling at $700^{\circ} \mathrm{C}^{32)}$ Grain interior nucleation seems to be retarded in the presence of solute carbon and bulge nucleation appears to be slowed in the grades containing $\mathrm{Ti}$. (Ti-IF: $35 \mathrm{ppm} \quad \mathrm{C}, \quad 0.25 \% \mathrm{Mn}$, $0.012 \% \mathrm{Al}, 0.064 \% \mathrm{Ti}, 23 \mathrm{ppm} \mathrm{N}$, LC: $0.01 \% \mathrm{C}$, $0.24 \% \mathrm{Mn}, 0.021 \% \mathrm{Al}, 20 \mathrm{ppm} \mathrm{N}$, and Ti-ULC: $50 \mathrm{ppm} \mathrm{C}, 0.25 \% \mathrm{Mn}, 0.011 \% \mathrm{Al}, 0.016 \% \mathrm{Ti}, 23 \mathrm{ppm}$ N)

interior nucleation. This arises, most probably, from the reduced number of in-grain shear bands in these grades. The low levels of "bulge" nucleation seen in the two grades that contain Ti can be understood in terms of the pinning of grain boundaries by Ti based precipitates.

The preceding discussion suggests that in-grain shear bands must be present for $\{111\}$ recrystallization textures of adequate intensity to form in warm rolled steels. The influence of $\mathrm{C}$ and $\mathrm{Cr}$ on the strain rate sensitivity provides the mechanism through which these elements influence the recrystallization texture. It should be mentioned, however, that heavy in-grain shear banding is detrimental to the formation of $\{111\}$ components during annealing. This is true for cold rolled products that contain a high level of solute carbon during rolling. ${ }^{60)}$ And Ushioda et al. ${ }^{38)}$ have shown that rolling at temperatures corresponding to the DSA flow stress peak, which promotes intense in-grain shear banding, can also reduce the $\{111\}$ intensity after recrystallization.

The proposal that there exist two contradictory effects of in-grain shear banding on the development of the $\{111\}$ recrystallization texture can be used to explain the results obtained by Matsuoka et al. ${ }^{41)}$ The latter are illustrated in Fig. 29. The steel with $10 \mathrm{ppm}$ solute carbon displays a higher $\{111\}$ intensity overall after recrystallization than the higher carbon steel. This is undoubtedly strongly influenced by the effect of carbon during annealing. However, the main point here is that the lower carbon steel exhibits a peak while the higher carbon grade displays a trough in $\{111\}$ intensity after rolling at $500^{\circ} \mathrm{C}$. Due to the high strain rate used, rolling temperatures of around $500^{\circ} \mathrm{C}$ in Fig. 29 correspond to the DSA flow stress peak and the region of negative strain rate sensitivity (see Fig. 11). As a consequence, the addition of an interstitial solute at this temperature is

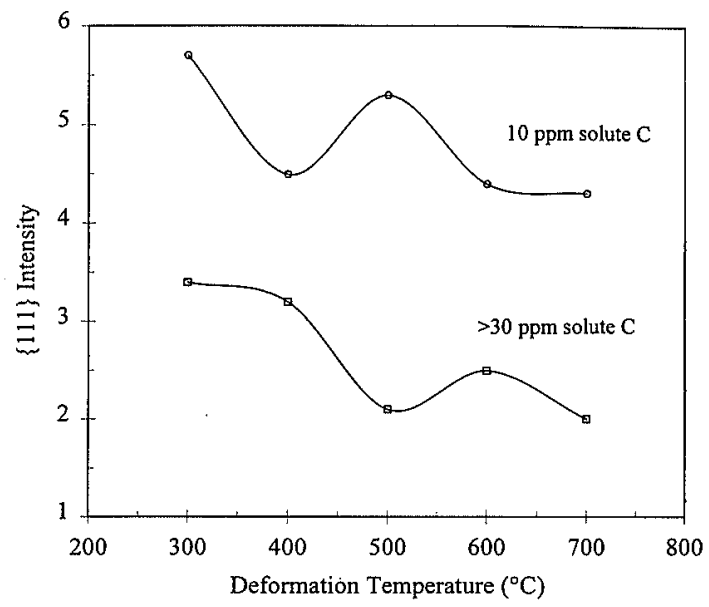

Fig. 29. Influence of rolling temperature on the $\{111\}$ texture intensity after recrystallization for steels of two different carbon levels $(34 \mathrm{ppm} \mathrm{C}, 0.15 \% \mathrm{Mn}$, $0.04 \% \mathrm{Al}, 0.015 \% \mathrm{Nb}, 20 \mathrm{ppm} \mathrm{N}$ and $0.043 \% \mathrm{C}$, $0.3 \% \mathrm{Mn}, 0.041 \% \mathrm{Al}, 40 \mathrm{ppm} \mathrm{N}){ }^{41}$ The strain rate used was $1000 / \mathrm{s}$, so the anomaly in the two curves at about $500^{\circ} \mathrm{C}$ coincides with DSA and a maximum in in-grain shear band frequency.

expected to rapidly increase the amount of in-grain shear band formation. The distinct peak in $\{111\}$ intensity in the $10 \mathrm{ppm} \mathrm{C}$ grade is most probably due to a moderate increase in in-grain shear banding. At higher carbon levels, the peak in $\{111\}$ intensity becomes a trough, presumably due to the formation of overly severe in-grain shear bands.

The discussion so far has centred around the $\{111\}$ texture. The orientations that form in the absence of $\{111\}$ components in LC materials will now be considered. It appears that the particular subgrain rotations observed by Senuma et al. ${ }^{32)}$ (see Fig. 13) are important here. Although these rotations do not seem to be linked to the presence of solute $\mathrm{C}$ as closely as first thought, they do account, in part, for the $\{112-001\}\langle 110\rangle$ recrystallization textures observed in these grades. Such textures nucleate at the grain boundaries between $\{111\}$ grains, in the regions where Senuma et al. observed distinct subgrain rotations. The measured orientations associated with this type of nucleation are illustrated in Fig. 30, in which the inverse pole figures obtained using EBSD analysis are illustrated. The high degree of bulge nucleation, which favours the $\{001\}\langle 110\rangle$ orientation, occurring in these grades (see Fig. 28) also contributes to the textures formed in the absence of $\{111\}$ orientations.

In the case of interstitial free steels, the $\{111\}$ intensity after recrystallization has been found to be favoured by low deformation temperatures and high strain rates. ${ }^{56,61)}$ One reason for this is that the higher energy structures produced under these conditions favour $\{111\}$ nucleation. ${ }^{61)}$ The temperature also influences the strain rate sensitivity in the absence of solute $\mathrm{C}$ or N. Figure 7 shows that the rate sensitivity begins to increase markedly with temperature for homologous temperatures above 0.5 . Such an increase in rate sensitivity is expected to diminish the extent of in-grain shear banding and consequently, according to the present line of reasoning, 
IF Steel

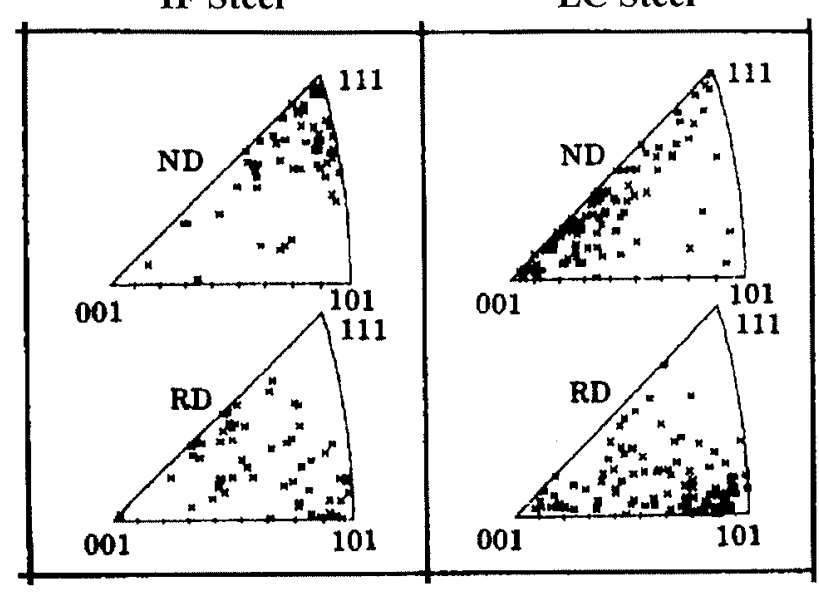

Fig. 30. Inverse pole figure representations of the orientations of the recrystallization nuclei formed at the grain boundaries separating deformed $\{11\}$ grains in an LC steel $(0.01 \% \mathrm{C}, 0.24 \% \mathrm{Mn}, 0.021 \% \mathrm{Al}, 20 \mathrm{ppm}$ $\mathrm{N})$ and an IF grade ( $35 \mathrm{ppm} \mathrm{C}, 0.25 \% \mathrm{Mn}, 0.012 \% \mathrm{Al}$, $0.064 \% \mathrm{Ti}, 23 \mathrm{ppm} \mathrm{N}){ }^{321}$

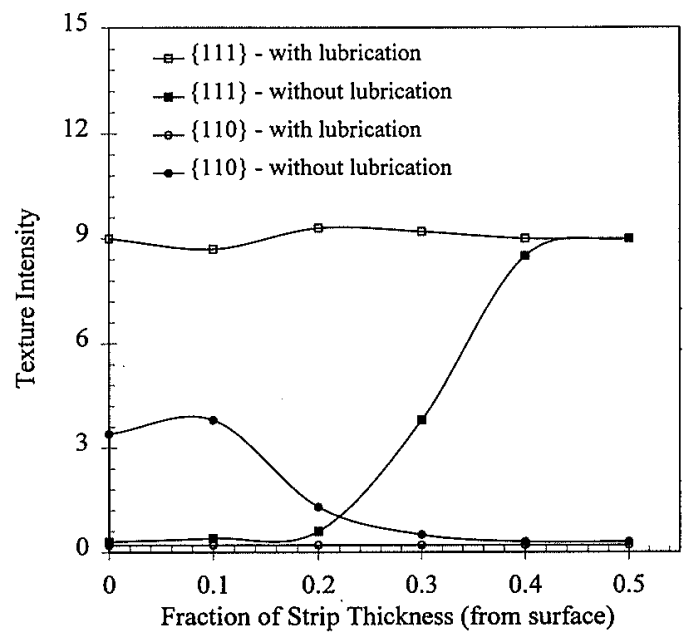

Fig. 31. Influence of lubrication on the $\{111\}$ texture intensity of a warm rolled and annealed IF steel $(60 \mathrm{ppm} \mathrm{C}$, $0.19 \% \mathrm{Mn}, 0.018 \% \mathrm{Al}, 0.081 \% \mathrm{Ti}, 43 \mathrm{ppm} \mathrm{N}){ }^{43)}$ Appropriate lubrication increases the $\{111\}$ intensity in the region near the strip surface.

the intensity of the $\{111\}$ texture after annealing.

\subsubsection{Surface Textures}

Friction in the roll bite leads to a gradient in the rolling texture through the strip thickness. As would be expected, this effect has a marked influence on the recrystallization texture. Fig. 31 ${ }^{43)}$ displays the intensities of the $\{111\}$ and $\{110\}$ components after rolling an IF steel to $65 \%$ reduction at $700^{\circ} \mathrm{C}$ and annealing at $850^{\circ} \mathrm{C}$. It is clear that, in the absence of effective lubrication, the $\{111\}$ intensity is depleted in the region within $1 / 3$ of the strip thickness from the surface. (Texture gradients also arise during conventional hot rolling but the severity of the gradient is appreciably reduced by the randomising effect of the $\gamma$-to- $\alpha$ phase transformation on the texture. This is why the use of lubricants is much less important during hot rolling.)

Many workers have examined this effect because of its

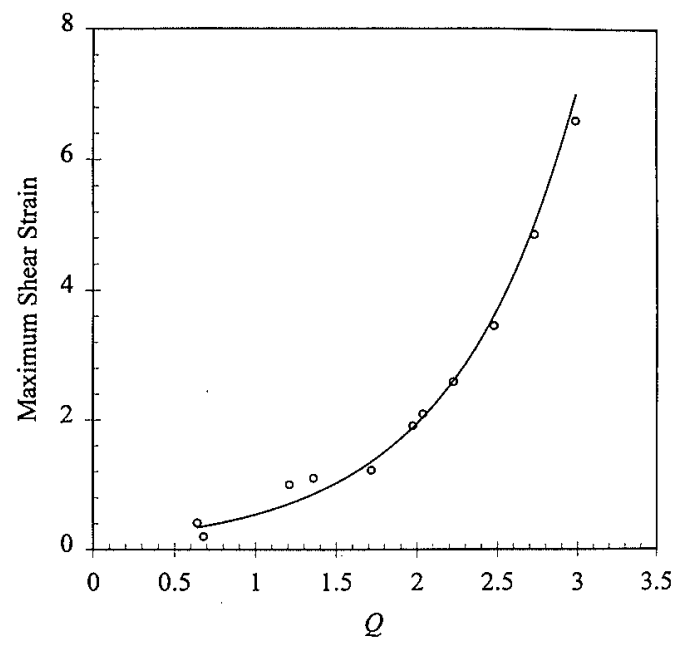

Fig. 32. Influence of friction hill parameter $Q$ (see text), which contains the friction coefficient, contact length and average thickness, on the maximum shear strain occurring during rolling ${ }^{66.67)}(\mu: 0.1-0.3$, reduction: $5-45 \%$, initial thickness: $1-5 \mathrm{~mm}$, roll radius: 35-355 mm).

negative impact on the drawing properties. For obvious reasons, these studies have concentrated on the influence of lubrication. ${ }^{56,62,63)}$ It appears that the lubrication conditions required for the $\{111\}$ intensity to remain high throughout the strip thickness are quite stringent. For example, Matsuoka et al. ${ }^{63)}$ and Senuma ${ }^{59)}$ recommend sufficient lubrication to bring the friction coefficient to levels below 0.15 . However, there are other factors that determine the surface shear strain, and consequently the heterogeneity of the recrystallization texture. These include strip thickness, rolling reduction, roll diameter and, particularly in the sticking friction regime, flow stress.

To describe the influence of these parameters on the shear strain comprehensively requires detailed mathematical modelling. Schmitz and Herman ${ }^{64)}$ have compiled such a model and have successfully predicted the shear strains arising from friction effects. However, a rough idea of the influence of the rolling conditions on the shear strain can be gained by examining the factors upon which the friction pressure hill depends. The following parameter has been used to describe the magnitude of the friction hill ${ }^{65)}$ :

$$
Q=\frac{2 \mu \sqrt{R\left(h_{0}-h_{1}\right)}}{h_{0}+h_{1}}
$$

where $\mu$ is the friction coefficient, $R$ is the roll radius, and $h_{0}$ and $h_{1}$ are the initial and final thicknesses. Roughly speaking, $Q$ is greater when the friction pressure hill is higher. The shear strain is plotted against this parameter in Fig. 32, for data obtained from references $^{66,67)}$ (roll flattening is ignored in these results). It is clear that the maximum shear strain is closely correlated with the value of $Q$. From Eq. (7), it is evident that the shear strain is reduced when the roll radius is decreased, the reduction is lowered, the strip thickness is increased, and the coefficient of friction is decreased. Further examination shows that, in most cases, a single 
Table 3. Five different types of warm rolled products (the references in bold include data obtained from full scale production or mill trials)

\begin{tabular}{ccccccccccc}
\hline & Type & Product & Grade & $\begin{array}{c}\text { Coiling } \\
\text { Temp. }\end{array}$ & Gauge & $\begin{array}{c}\text { Pre- } \\
\text { Anneal }\end{array}$ & $\begin{array}{c}\text { Cold } \\
\text { Roll }\end{array}$ & Anneal & Galv. & References \\
\hline 1 & Hot Band & CQ & LC & high & thin & & & & & $1,18,55,71,73$ \\
2 & $"$ & CQ-DDQ & LC-IF & low & thin & & & $\checkmark$ & $(\checkmark)$ & $4,55,61,68,71,73$ \\
3 & Cold Band & CQ-DQ & LC & high & normal & & $\checkmark$ & $\checkmark$ & $(\checkmark)$ & $\mathbf{1 , 2 , 6 , 6 9 , 7 0 , 7 2 , 7 4}$ \\
4 & $"$ & CQ-DQ & LC-IF & low & normal & & $\checkmark$ & $\checkmark$ & $(\checkmark)$ & $\mathbf{2 , 4 , 6 9 , 7 0 , 7 2}$ \\
5 & $"$ & DQ-SDDQ & IF & low & normal & $\checkmark$ & $\checkmark$ & $\checkmark$ & $(\checkmark)$ & $56,63,59$ \\
\hline
\end{tabular}

Table 4. Benefits that can be realised through the implementation of warm rolling.

\begin{tabular}{|c|c|c|c|}
\hline & Products & Comments & Ref.s \\
\hline \multicolumn{4}{|l|}{ Warm Rolling } \\
\hline increased furnace throughput & all & only if using low reheat tempcratures & 6 \\
\hline less energy usage & $"$ & $"$ & $1,2,6$ \\
\hline less scale loss & $"$ & $"$ & 2 \\
\hline less damage to slabs & $"$ & $"$ & 2 \\
\hline reduced roll wear & $"$ & less roll changes, higher productivity & 1 \\
\hline less water on run-out table & 1.3 & only for high coiling temperatures & 1 \\
\hline less streaking (Ti-IF) & $2,4.5$ & only if using low reheat temperatures & 2 \\
\hline thinner gauge & all & where heat loss limits gauge & 1,6 \\
\hline \multicolumn{4}{|l|}{ Pickling } \\
\hline increased throughput & all & due to thinner scale layer & 2,6 \\
\hline increased throughput & 3 & only if hot band gauge is increased & 74 \\
\hline less acid usage & all & & 6 \\
\hline \multicolumn{4}{|l|}{ As-Warm Rolled Products } \\
\hline softer & 1 & only for high coiling temperatures & 1.6 \\
\hline higher r-value & 2 & only if using lubrication & 56 \\
\hline non-ageing & 1.2 & only if using low reheat temperatures & 74 \\
\hline \multicolumn{4}{|l|}{ Cold Rolling } \\
\hline lower rolling loads & $3 .(4)$ & mostly for high coiling temperatures & 1,6 \\
\hline increased throughput & 3 & $"$ & 1 \\
\hline less roll wear & 3 & $"$ & 1,6 \\
\hline \multicolumn{4}{|l|}{ Cold Rolled Products } \\
\hline higher r-value & 5 & only if using lubrication in warm rolling & 63 \\
\hline softer & 3 & only for high coiling temperatures & 6 \\
\hline
\end{tabular}

pass reduction leads to lower total shear strain than that expected from carrying out the same total reduction in more than one pass.

\section{Some Practical Issues}

An interesting feature of warm rolling is that steel companies who have studied or implemented it have done so for different reasons. There are many arguments in favour of this process, and a few contrary ones. The variety of driving forces in favour of warm rolling stems from the different types of products it can be used to produce. Table 3 itemises five main product types that have been addressed in the warm rolling literature. $1,2,4,6,18,55,56,59,61,63,68-74)$

Some of the benefits that are realised in the production of these warm rolled products are listed in Table 4. It is of interest to mention that warm rolling can lead to considerable benefits in the production of basic $C Q$ grades as well as of the specialised super deep drawing quality grades. Of particular note is the opportunity opened up by warm rolling of producing hot band with properties that have been traditionally met by cold rolled material (especially product type 2 in Table 3 ). This, combined with thin hot strip rolling, paves the way for the replacement of cold rolled products by hot rolled grades. A significant opportunity in this category of product is that of producing material with a very thin, and therefore readily pickled, scale layer. Some simulations of scale thickness based on the equation of Browne et al. ${ }^{75)}$ are illustrated in Fig. 33. These calculations suggest that low temperature warm rolling may lead to scale layers less than $2 \mu \mathrm{m}$ in thickness.

The most common application of warm rolling is simply as a substitute for hot rolling in the production route of normal products. The final sheet after warm rolling, cold rolling and annealing has properties that are similar to, or marginally better than, those produced using hot rolling followed by cold rolling and annealing. ${ }^{1,2,6)}$ The benefits, in this case, are realised in the cost and rate of production.

Of course, warm rolling also gives rise to new risks and potential problems. Many of these stem from the metallurgical peculiarities addressed above. For in- 


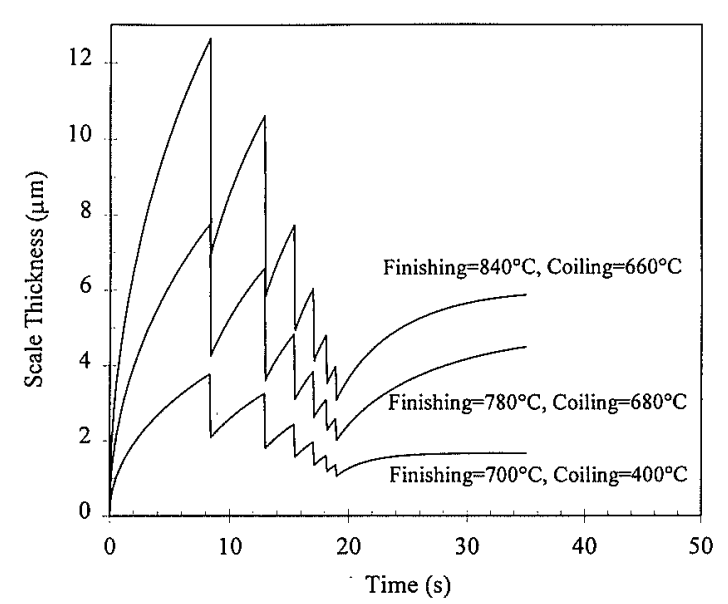

Fig. 33. Simulation of scale thickness produced after rolling a $27 \mathrm{~mm}$ transfer bar down to $2 \mathrm{~mm}$ in a 6 -stand finishing mill, using a simple scale model. ${ }^{75}$ Warm rolling combined with low coiling temperatures may be used to produce a 5 -fold decrease in scale layer thickness, compared to that formed on typical products.

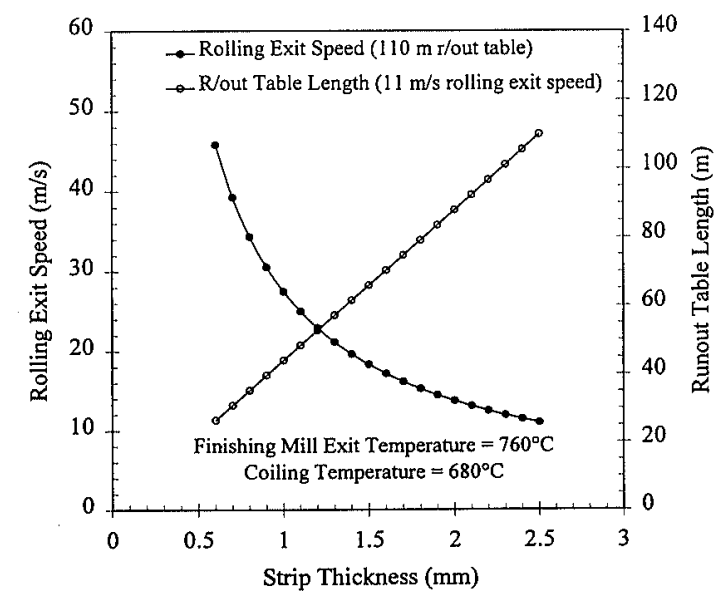

Fig. 34. Influence of final strip thickness on minimum rolling speed and maximum runout table length, for a finishing mill exit temperature of $760^{\circ} \mathrm{C}$ and a coiling temperature of $680^{\circ} \mathrm{C}$ (assuming air cooling on the runout table).

stance, the consistent production of high $r$-value "hot" band requires careful control of lubrication, degree of stabilisation (for IF products), ${ }^{11.76)}$ reheat temperature ${ }^{63)}$ and rolling reduction. For the production of soft warm rolled strip, the coiling temperature must be above a minimum level. For standard LC grades, this temperature falls around $650-670^{\circ} \mathrm{C}$. Coiling temperatures below this limit will result in deformed material remaining in areas of the strip, specifically at the cooler ends and edges. This, in turn, may give rise to shape and or edge problems during cold rolling and in the final product.

For a given finishing temperature, such a limitation on coiling temperature translates into a limitation on rolling speed, strip thickness and runout table length. This is illustrated in Fig. $\mathbf{3 4}$ for the case where only air cooling is used. In reality, some cooling water is applied for control and scale reasons, so Fig. 34 is a "best-case" scenario for the conditions given.
The gradient in recrystallization texture in unlubricated products can also lead to forming problems other than those associated with low $r$-values. Preliminary results ${ }^{77)}$ suggest that the ability of warm rolled, then cold rolled and recovery annealed products to be bent around small radii is low. This problem is alleviated in the absence of through-thickness texture gradients.

\section{Conclusions}

The present review has shown that a surprising amount of the physical metallurgy of warm rolling differs from that applicable to hot or cold rolling. This observation is a consequence of four distinctive features of the process:

(i) Warm rolling often involves deformation and restoration in the two-phase region. Hot rolling is confined to austenite deformation and cold rolling to working of the ferrite phase. The presence of a second phase interferes with the deformation and softening mechanisms of the primary phase, and vice versa. This has not been given much attention in the literature and is an area requiring further work if the microstructural evolution during warm rolling is to be accurately modelled.

(ii) Solute carbon interacts with dislocations during warm rolling in a manner quite unlike that seen either in cold or in hot rolling. This occurs because of the combination of high carbon mobility and the strength of the $\mathrm{C}$ atom interaction with dislocations. As a consequence, high strain rate sensitivities and low levels of in-grain shear band formation accompany the presence of solute carbon. The relative absence of in-grain shear bands under these conditions has a major impact on texture development and recrystallization.

(iii) The effects of the shear strain arising from friction forces in the roll bite on the texture are more prominent than those seen in hot rolling. This occurs for a number of reasons. Firstly, there is no transformation after rolling to randomise the texture. Secondly, there is a greater chance of accumulating surface shear strain during warm rolling due to the ease of avoiding interpass recrystallization when using lower rolling temperatures. And thirdly, higher roll forces, and hence higher friction forces, are possible in warm rolling.

(iv) Warm rolling may be used to produce $\{111\}$ deep drawing textures. This has traditionally been the domain of cold rolling and annealing. As a consequence, little indication existed previously as to the likely impact of hot strip mill rolling parameters on the intensity of the $\{111\}$ recrystallization texture of warm rolled strip.

The metallurgical issues stemming from these features pose difficulties for the steel producer; nevertheless they also open up new opportunities in process and product optimisation.

\section{Acknowledgements}

The authors are grateful to BHP Steel Products for permission to publish this paper and for sponsoring 
one of the authors' (MB) research on warm rolling. JJJ acknowledges with gratitude the Visiting Fellowship received from the Japan Society for the Promotion of Science (host: Professor Taku Sakai). The final version of this review was prepared during the tenure of this award at the University of Electro-Communications in Tokyo.

\section{REFERENCES}

1) P. Harlet, F. Beco, P. Cantinieaux, D. Bouquegneau, P. Messien and J. C. Herman: Int. Symp. On Low C Steels for the 90's, ed. by R. Asfahani and G. Tither, TMS-AIME, Warrendale, PA, (1993), 389

2) W. H. Parks, C. S. Haggerty and T. R. Rock: Iron Steel Eng., (1997), 35.

3) H. Grossheim, K. Schotten and W. Bleck: J. Materials Process. Technol, 60 (1996), 609.

4) P. Messien, J. C. Herman, V. Leroy, Ph. Harlet, F. Beco and L. Renard: Developments in the Annealing of Sheet Steels, ed. by R. Pradhan and I. Gupta, TMS-AIME, Warrendale, PA, (1992), 287.

5) M. Unemoto, A. Hiramatsu, A. Moriya, T. Watanabe, S. Nanba, N. Nakajima, G. Anan and Y. Higo: ISIJ Int., 32 (1992), 306.

6) P. A. Bagshaw and R. J. Kimber: Int. Conf. on Thermomechanical Processing of Steels and Other Materials (THERMEC'97), ed. by T. Chandra and T. Sakai, TMS-AIME, Warrendale, PA, (1998), 147. (Plus personal communications.)

7) Y. Saito: Trans. Iron Steel Inst. Jpn., 27 (1987), 419.

8) D. Vanderschueren, L. Kestens, P. Van Houtte, E. Aernoudt, J. Dilewijns and U. Meers: Mater. Sci. Technol., 6 (1990), 1247.

9) E. A. Simielli, S. Yue and J. J. Jonas: Metall. Trans. A, 23A (1992), 597.

10) M. R. Barnett, P. D. Hodgson and J. J. Jonas: 37th MWSP Conf. Proc., ISS, Warrendale, PA, XXXII (1995), 385.

11) T. Senuma and H. Yada: Int. Conf. on Thermomechanical Processing of Steels and Other Materials (THERMEC'88), ed. by I. Tamura, TMS-AIME, Warrendale, PA, (1988), 636.

12) A. Schmickl, D. Yu, C. Killmore, D. Langley and T. Chandra: ISIJ Int., 36 (1996), 1279.

13) A. Laasraoui and J. J. Jonas: Metall. Trans. A, 22A (1991), 1545.

14) H. J. McQueen, W. Blum, Q. Zhu and V. Demuth: Advances in Hot Deformation Textures and Microstructures, TMS-AIME, Warrendale, PA, (1994), 235.

15) A. Schmitz: Doctoral Thesis, Univ. of Leuven, Belgium, (1995).

16) M. R. Barnett, G. Hamilton and W. Y. D. Yuen: Materials '98, ed. by M. Ferry, IMEA, Wollongong, (1998), 153.

17) M. R. Barnett and J. J. Jonas: ISIJ Int., 37 (1997), 697.

18) M.R. Barnett: Modern LC and ULC Sheet Steels for Cold Forming: Processing and Properties, ed. by W. Bleck, Verlag Mainz, Aachen, (1998), 61.

19) J. D. Baird and A. Jamieson: J. Iron Steel Inst., (1966), 793.

20) A. H. Cottrell: Dislocations and Plastic Flow in Crystals, Oxford University Press, London, (1953), 136.

21) M. R. Barnett: Materials '98, ed. by M. Ferry, IMEA, Wollongong, (1998), 167

22) J. Glen: J. Iron Steel Inst., (1957), 21

23) K. Osakada and S. Fujii: J. Mech. Work. Technol., 2 (1978), 241

24) E. V. Subramanian and D. L. Bourell: J. Appl. Metalwork., 3 (1984), 264

25) A. S. Keh, Y. Nakada and W. C. Leslie: Dislocation Dynamics, ed. by A. R. Rosenfield, G. T. Hahn, A. L, Bement, Jr, and R. L Jaffee, McGraw-Hill, New York, (1967), 381.

26) G. E. Dieter: Mechanical Metallurgy, McGraw-Hill, London, (1988), 535 .

27) G. Glover and C. M. Sellars: Metall. Trans., 4 (1973), 765.

28) T. Takeyama and H. Takahashi: Trans. Iron Steel Inst. Jpn., 13 (1973), 293

29) R. J. McElroy and Z. C. Szkopiak: Int. Metall. Rev., 17 (1972), 175.

30) J. J. Jonas, C. M. Sellars and W. J. McG. Tegart: Metall. Rev., Review 130, (1969), 1.
31) Y. Matsubara, N. Tsuji and Y. Saito: Int. Conf. on Thermomechanical Processing of Steels and Other Materials (THERMEC'97), ed. by T. Chandra and T. Sakai, TMS-AIME, Warrendale, PA, (1997), 653.

32) T. Senuma, H. Yada, R. Shimizu and J. Harase: Acta Metall. Mater., 38 (1990), 2673.

33) M. R. Barnett: CRM Internal Report, (1997).

34) M. R. Barnett: ISIJ Int., 38 (1998), 78.

35) G. H. Akbari, C. M. Sellars and J. A. Whiteman: Acta Metall. Mater., 45 (1997), 5047.

36) B. Bay, N. Hansen, D. A. Hughes and D. Kuhlmann-Wilsdorf: Acta Metall. Mater., 40 (1992), 205.

37) D. A. Hughes and N. Hansen: Metall. Trans. A, 24A (1993), 2021.

38) K. Ushioda, H. Ohsone and M. Abe: Proc. 6th Int. Conf. on Textures of Materials (ICOTOM 6), ISIJ, Tokyo, (1981), 829.

39) A. Korbel, J. D. Embury, M. Hatherly, P. L. Martin and H. W. Erbsloh: Acta Metall., 34 (1986), 1999.

40) S. L Semiatin and J. J. Jonas: Formability and Workability of Metals-Plastic Instability and Flow Localisation, ASM, Metals. Park, Ohio, (1984), 43.

41) S. Matsuoka, K. Sakata, S. Satoh and T. Kato: Textures Microstruct., 22 (1993), 113.

42) E. Aernoudt, P. Van Houtte and T. Leffers: Materials Science and Technology-A Comprehensive Treatment, Vol. 6, VCH, Wcinhcim, (1993), 89.

43) T. Sakai, Y. Saito and K. Kato: Trans. Iron Steel Inst, Jpn., 28 (1988), 1037.

44) Y. Shimizu, Y. Ito and Y. Iida: Metall. Trans. A, 17A (1986), 1323

$45)$ R. D. Doherty, D. A. Hughes, F. J. Humphreys, J. J. Jonas, D. Juul Jensen, M. E. Kassner, W. E. King, T. R. McNelley, H. J. McQueen and A. D. Rollett: Mater. Sci. Eng., A238 (1997), 219.

46) J. Baczynski and J. J. Jonas: Metall. Trans. A, 29A (1998), 447.

47) A. Najafi-Zadeh, J, J. Jonas and S. Yue: Metall. Trans. A, 23A (1992), 2607.

48) R. Z. Wang and T. C. Lei: Scr, Met. Mater., 31 (1994), 1193.

49) S. Gohda, K. Watanabe and Y. Hashimoto: Trans. Iron Steel Inst. Jpn., 21 (1981), 6.

50) S. Gourdet and F. Monthelliet: J. Phys., 5 (1994), 255.

51) P. R. Cetlin, S. Yue, J. J. Jonas and T. M. Maccagno: Metall. Trans. A, 24A (1993), 1543.

52) M. R. Barnett: BHP Steel, unpublished work, (1998)

53) H. Langner, W. Bleck and C. Greisert: Modern LC and ULC Sheet Steels for Cold Forming: Processing and Properties, 1, ed. by W. Bleck, Verlag Mainz, Aachen, (1998), 301.

54) M. R. Barnett and J. J. Jonas: ISIJ Int., 37 (1997), 706

55) M. R. Barnett, J. J. Jonas and P. D. Hodgson: Iron Steelmaker, (1996), 39.

56) T. Senuma and K. Kawasaki: ISIJ Int., 34 (1994), 51.

57) B. J. Duggan, H. Ning and L. X. Zhang: Int. Conf. on Thermomechanical Processing of Steels and Other Materials (THERMEC'97), ed. by T. Chandra and T. Sakai, TMS, Warrendale, PA, (1998), 2305.

58) D. Vanderschueren, N. Yoshinaga and K. Koyama: ISIJ Int., 36 (1996), 1046.

59) T. Senuma: Modern LC and ULC Sheet Steels for Cold Forming: Processing and Properties, ed. by W. Bleck, Verlag Mainz, Aachen, (1998), 157.

60) W. B. Hutchinson: Int. Met. Rev, 29 (1984), 25.

61) S. Matsuoka, K. Sakata, S. Satoh and T. Kato: ISIJ Int., 34 (1994), 77.

62) P. Messien and J. Herman in Int. Symp. on Low C Steels for the 90's, Ed. by R. Asfahani and G. Tither, TMS-AIME, Warrendale, PA, (1993), 383

63) S. Matsuoka, K. Sakata, O. Furukimi and T. Obara: Modern LC and ULC Sheet Steels for Cold Forming: Processing and Properties, Ed. by W. Bleck, Verlag Mainz, Aachen, (1998), 85.

64) A. Schmitz and J-C. Herman: Ist Int. Conf. on Modelling Metal Rolling Processes, Institute of Materials, London, (1993), 438.

65) V. B. Ginzburg: Steel Rolling Technology; Theory and Practice, Marcel Dekker, NY, (1989), 227, 241.

66) T. Sakai, Y. Saito, K. Hirano and K. Kato: Trans. Iron Steel Inst. Jpn., 28 (1988), 1028.

67) S. Matsuoka, M. Morita, O. Furukimi and T. Obara: ISIJ Int., 
38 (1998), 633.

68) R. F. Gadellaa, P. J. Freijer, M. C. M. Cornelissen, B. Donnay, J. C. Herman and V. Leroy: Proc. METEC Cong. 94, Verein Deutscher Eisenhüttenleute, Dusseldorf, (1994), 382.

69) L. Meyer, W. Bleck and T. Heidelhauf: Int. Symp. on Low-Carbon Steels for the 90's, ed. by R. Asfahani and G. Tither, TMS, Warrendale, PA, (1993), 427.

70) O. Kwon, G. Kim and R. W. Chang: Metallurgy of VacuumDegassed Steel Products, Ed. by R. Pradhan, TMS-AIME, Warrendale, PA, (1990), 215.

71) V. Leroy and J. C. Herman: Microalloying '95, ISS, Warrendale, PA, (1995), 213.

72) S. Claessens, D. Vanderschueren, D. Bultinck, I. Bungelman and J. Dilewijns: Hot Workability of Steels and Light Alloys-
Composites, CIM, Montreal, (1996), 341.

73) S. Hashimoto, T. Kashima, N. Nakajima, H. Shirasawa and M. Miyahara: Metallurgy of Vacuum-Degassed Steel Products, ed. by R. Pradhan, TMS-AIME, Warrendale, PA, (1990), 357.

74) R. Smith, P. Edwards and J. Dock: BHP Steel, unpublished work, (1997)

75) K. M. Browne, J. Dryden and M. Assefpour: Recent Advances in Heat Transfer and Micro-Structure Modelling for Metal Processing, MD-Vol. 67, Ed. by R-M. Guo and J. J. M. Too, ASME, New York, (1995), 187.

76) A. De Paepe, J-C. Herman and V. Leroy: Steel Res., 68 (1997), 479.

77) M. R. Barnett: BHP Steel, unpublished work, (1998). 